\title{
Kinetic control of translation initiation in bacteria
}

\author{
Pohl Milón and Marina V. Rodnina \\ Department of Physical Biochemistry, Max Planck Institute of Biophysical Chemistry, Goettingen, Germany
}

\begin{abstract}
Translation initiation is a crucial step of protein synthesis which largely defines how the composition of the cellular transcriptome is converted to the proteome and controls the response and adaptation to environmental stimuli. The efficiency of translation of individual mRNAs, and hence the basal shape of the proteome, is defined by the structures of the mRNA translation initiation regions. Initiation efficiency can be regulated by small molecules, proteins, or antisense RNAs, underscoring its importance in translational control. Although initiation has been studied in bacteria for decades, many aspects remain poorly understood. Recent evidence has suggested an unexpected diversity of pathways by which mRNAs can be recruited to the bacterial ribosome, the importance of structural dynamics of initiation intermediates, and the complexity of checkpoints for mRNA selection. In this review, we discuss how the ribosome shapes the landscape of translation initiation by non-linear kinetic processing of the transcriptome information. We summarize the major pathways by which mRNAs enter the ribosome depending on the structure of their $5^{\prime}$ untranslated regions, the assembly and the structure of initiation intermediates, the individual and synergistic roles of initiation factors, and the mechanisms of mRNA and initiator tRNA selection.
\end{abstract}

Keywords: protein synthesis, translation initiation, ribosome function, mRNA selection, regulation of gene expression, RNA, RNA-protein complex assembly, translation initiation factors

\section{Overview of translation initiation}

During initiation, the ribosome, assisted by initiation factors, recruits the mRNA to be translated and defines the reading frame by identifying a start codon. Initiation is often referred to as the rate-limiting step of translation (Jacques \& Dreyfus, 1990; Laursen et al., 2005; Kudla et al., 2009); however, other reports suggested that initiation is rapid compared to the elongation phase of protein synthesis (Mitarai et al., 2008). In bacteria, newly synthesized mRNA can be recruited into translation while still being transcribed. However the predominant mRNA species is the full-length transcript, which is apparent from the quantitative RNA sequencing of an entire bacterial transcriptome (Passalacqua et al., 2009). Furthermore, the duration of transcription elongation, and hence the phase at which coupled transcriptiontranslation is possible, is much shorter (about $25 \mathrm{~s}$ for a 1 kb gene; (Proshkin et al., 2010)) than the known mRNA lifetimes (between 4 and $11 \mathrm{~min}$ for Escherichia coli transcripts (Bernstein et al., 2002)), indicating that a bulk of mRNAs are translated post-transcriptionally. Usually one mRNA is translated by multiple ribosomes, which successively load on the mRNA with an interval of 2-4 s to form polysomes (Mitarai et al., 2008). At conditions where the availability of ribosomes is limited, assembly of the initiation complex may depend on the efficient ribosome recycling, which is facilitated by the ribosome recycling factor (RRF) and elongation factor G (EF-G). As the recovery of ribosomes after termination of translation on a given mRNA is quite slow $\left(<1 \mathrm{~s}^{-1}\right.$ measured with components from E. coli (Karimi et al., 1999; Peske et al., 2005)), ribosome recycling may limit the effective rate of initiation. Exactly which step of translation is ratelimiting for the translation of a given mRNA may depend on the efficiency of its translation initiation region (TIR), the codon usage along the coding sequence, and growth conditions.

In bacteria, translation initiation requires the action of three initiation factors, IF1, IF2, and IF3, and the initiator tRNA, fMet-tRNA ${ }^{\mathrm{fMet}}$. Initiation proceeds through three main phases (Figure 1). During the first phase, mRNA, IFs, and fMet-tRNA ${ }^{\mathrm{fMet}}$ bind to the small (30S)

Address for Correspondence: Marina V. Rodnina, Department of Physical Biochemistry, Max Planck Institute of Biophysical Chemistry, Am Fassberg 11, 37077 Goettingen, Germany. Tel: +49 551201 2901. E-mail: rodnina@mpibpc.mpg.de 


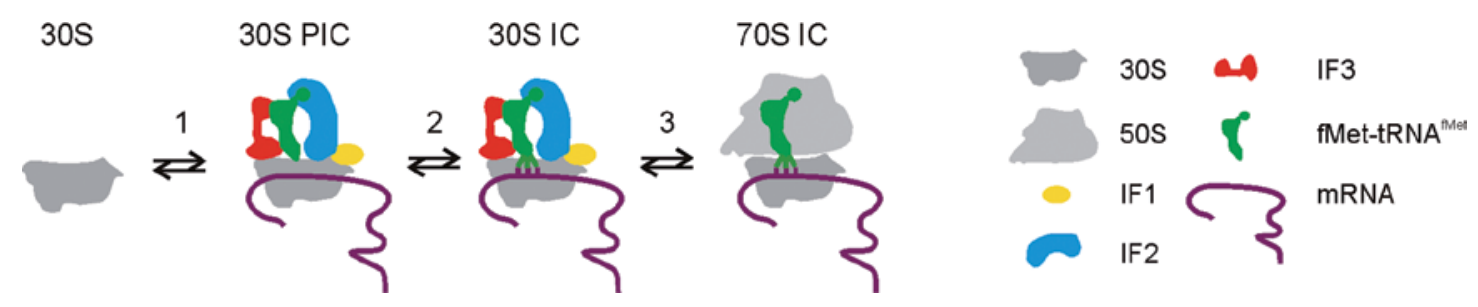

Figure 1. Schematic of the three main phases of translation initiation. Phase 1: Assembly of the 30S PIC upon recruitment of initiation factors, mRNA, and fMet-tRNA ${ }^{\text {fMet }}$ to the $30 \mathrm{~S}$ subunit. Phase 2: Conversion of 30S PIC to 30S IC after start codon recognition by fMet$\mathrm{tRNA}^{\mathrm{fMet}}$. Phase 3: Formation of the 70S IC following 50S subunit joining and release of initiation factors. (See colour version of this figure online at www.informahealthcare.com/bmg)

ribosomal subunit to assemble into a transient $30 \mathrm{~S}$ preinitiation complex (30S PIC). The 30S PIC is converted to a functional 30 S initiation complex (30S IC) when the interaction between the start codon and the anticodon of fMet-tRNA ${ }^{\mathrm{fMet}}$ in the $\mathrm{P}$ site is established. At the last phase, the large (50S) ribosomal subunit joins the $30 \mathrm{~S}$ IC forming the 70S initiation complex (70S IC), which is poised for the translation of the selected mRNA. Each of the three phases entails a number of distinct elemental steps, providing a complex network of interactions that contribute to translational control of gene expression and prevent the synthesis of aberrant polypeptides due to out-of-frame mRNA decoding.

\section{Initiation machinery}

In recent years, a number of structures of $30 \mathrm{~S}$ and $70 \mathrm{~S}$ ICs have been reported which revealed the positions and orientations of the initiation components. Bioinformatics provided unprecedented insights into the diversity of mRNAs in different organisms. Rapid kinetics and singlemolecule FRET studies unraveled the timing of events and the molecular choreography of initiation. In this chapter, we summarize recent advances in structural and functional studies of IF1, IF2, IF3 and the mRNA recognition elements that define the start codon selection. The descriptions of structures of the ribosomal subunits and fMet-tRNA ${ }^{\mathrm{fMet}}$ can be found in in earlier reviews (Laursen et al., 2005; Allen \& Frank, 2007; Myasnikov et al., 2009; Simonetti et al., 2009).

\section{Initiation factors}

IF1 is a small (71 amino acid residues) basic protein comprised of a single domain that is formed by a fivestranded $\beta$-barrel belonging to the OB-fold family of proteins (Sette et al., 1997) (Figure 2A). The factor binds at the A site of the $30 \mathrm{~S}$ subunit in the vicinity of ribosomal protein S12, the 530 loop and helix 44 of $16 \mathrm{~S}$ rRNA (Carter et al., 2001). IF1 stabilizes the binding of IF2 and IF3 to the 30S subunit and modulates the selection of mRNA and fMet-tRNA ${ }^{\mathrm{fMet}}$ by controlling the conformational dynamics of the 30S subunit (see below) (Gualerzi et al., 1977; Milon et al., 2008; Milon et al., 2010).

IF2 is a multi-domain GTPase that plays a key role in the recruitment of fMet-tRNA ${ }^{\mathrm{fMet}}$ to the 30S PIC and in regulating the formation of the 70S IC. Based on the results of partial proteolysis and sequence alignments, the structure of IF2 was divided in the $\mathrm{N}$-terminal domain (N-domain, further divided into subdomains $\mathrm{Nl}$ and N2), the GTP-binding domain (G-domain, consisting of G1, G2, and G3), and the C-terminal domain (C-domain, subdomains $\mathrm{Cl}$ and C2) (Figure 2B). Subdomains G2, G3, C1, and C2 are highly conserved. G2 is the GTPbinding subdomain of IF2, whereas G3 is characteristic for all translational GTPases and is homologous to domain 2 of EF-Tu and EF-G. C2 contains the binding site for the $3^{\prime}$-end and the fMet moiety of fMet-tRNA ${ }^{\mathrm{fMet}}$ (Guenneugues et al., 2000). The N-domain may act as an additional anchor for IF2 on the 30S subunit (Moreno et al., 1999; Caserta et al., 2006; Julian et al., 2011). The subdomains N1, N2, and G1 vary both in amino acid composition and length among different bacterial species and are absent in archaea (Roll-Mecak et al., 2000).

The crystal structure of a full-length bacterial IF2 is not known so far. The structures of the $\mathrm{C} 1$ and $\mathrm{C} 2$ subdomains and of a small fragment of the $\mathrm{N}$-domain are available (Meunier et al., 2000; Laursen et al., 2003; Wienk et al., 2005). Recently, the structure of the G2 subdomain in the apo form and in complex with GDP has been solved by NMR (Wienk et al., 2012). Crystals of T. thermophilus IF2 have been reported (Simonetti et al., 2011), but the structure has not been released so far (as of January 2012). Otherwise, the knowledge on the IF2 structure is limited to homology models (Allen et al., 2005; Simonetti et al., 2009) derived from the crystal structure of the archaeal ortholog, eIF5B, from Methanobacterium thermoautotrophicum (Roll-Mecak et al., 2000). Recently, the structure of full-length $E$. coli IF2 was modeled using the density attributed to the factor in the cryo-EM structure of the E. coli 30 S IC (Julian et al., 2011) (Figure 2B). The model suggests that the three $\mathrm{N}$-terminal subdomains in IF2 fold into compact structures, rather than being disordered as thought previously (Allen \& Frank, 2007). On the 30 S subunit, the $\mathrm{N}$ domain of IF2 contacts IF1 and S12 (Julian et al., 2011), in agreement with the biochemical evidence suggesting that the isolated $\mathrm{N}$-domain of $E$. coli IF2 can bind to the 30S subunit (Mortensen et al., 1998; Moreno et al., 1999).

For a GTP-binding protein, IF2 is quite unusual. The affinity of GTP and GDP binding to IF2 is low, ranging between $1 \mu \mathrm{M}$ (GDP) (Hauryliuk et al., 2009) and 10-40 $\mu \mathrm{M}$ (GTP) (Milon et al., 2006; Hauryliuk et al., 2009). 
A

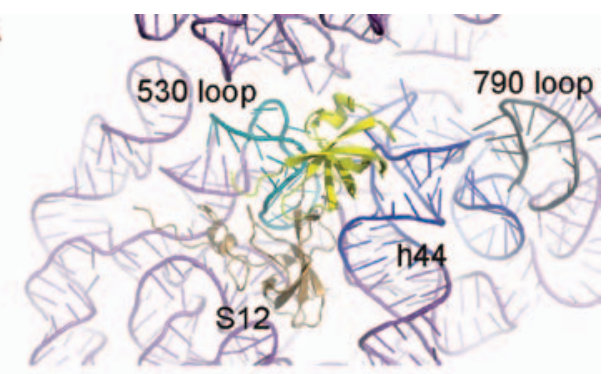

B
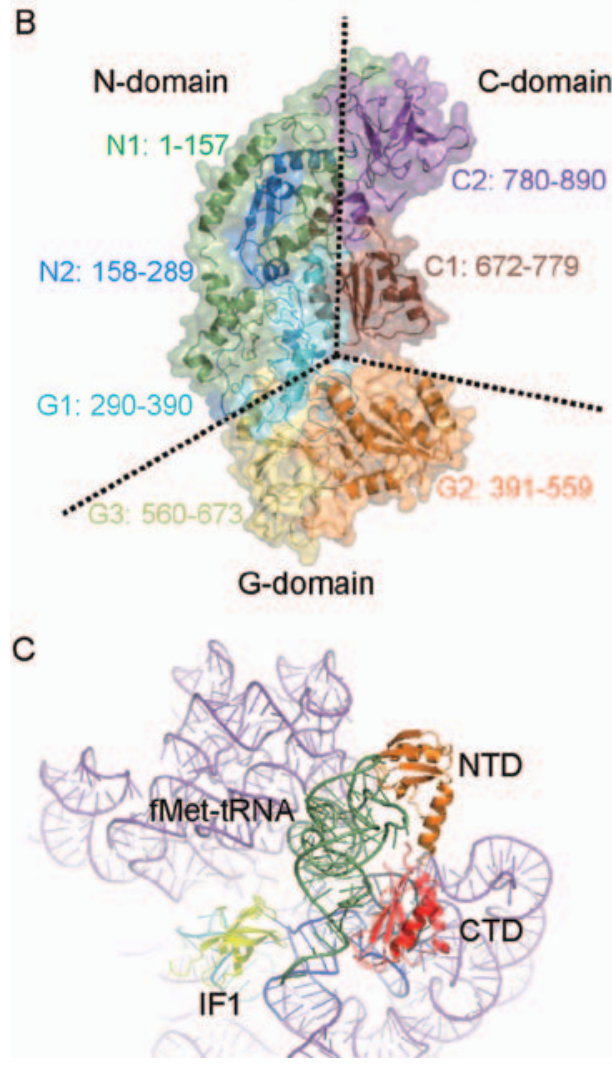

Figure 2. Structures of the initiation factors bound to the $30 \mathrm{~S}$ subunit. (A) IF1 (yellow; PDB 1AH9) bound at the A site of the 30S subunit in the vicinity of the ribosomal protein $\$ 12$ (sand), the 530 loop (cyan) and helix 44 (blue) of 16S rRNA (purple). The 790 loop (gray) is the binding site of IF3 (adapted from (Carter et al., 2001; Julian et al., 2011); PDB 1HRO). (B) Model of full-length E. coli IF2 in the 30S IC (adapted from (Julian et al., 2011)). IF2 subdomains are indicated; dotted lines mark the boundaries between the $\mathrm{N}$-terminal domains, the G2/G3 functional unit conserved in all translational GTPases, and the C-terminal domains of the protein. (C) IF3 in the 30S IC (adapted from (Julian et al., 2011)). IF3-NTD (orange; PDB ITIF) contacts the elbow region of fMettRNA $^{\text {fMet }}$ (green, PDB 2FMT). IF3-CTD (red, PDB 2IFE) is bound to the 790 loop of $16 \mathrm{~S}$ rRNA. The position of IF1 (yellow) is also indicated. (See colour version of this figure online at www. informahealthcare.com/bmg)

Nucleotide exchange is spontaneous due to the high rate of nucleotide dissociation (Milon et al., 2006). Isothermal titration calorimetry and small-angle X-ray scattering analyses suggested that IF2 changes conformation when going from ligand-free to the GDPNP-or GDP-bound forms (Pon et al., 1985; Hauryliuk et al., 2009; Vohlander Rasmussen et al., 2011), although the magnitude of these changes remains uncertain. IF2 binds fMet-tRNA ${ }^{\mathrm{fMet}}$ with micromolar affinity forming a labile complex that dissociates rapidly ((Milon et al., 2010) and references therein). In contrast to other translation factors capable of forming complexes with tRNAs, such as EF-Tu, SelB, or eIF2, the formation of the IF2.fMet-tRNA ${ }^{\text {fMet }}$ complex does not require GTP (Mitkevich et al., 2010), which would be quite unusual if the complex were the physiological vehicle for the delivery of the tRNA to the ribosome. In fact, the complex has to dissociate before the tRNA can be recruited to the 30S PIC (Milon et al., 2010). Rather, the complex IF2.fMet-tRNA ${ }^{\mathrm{fMet}}$ might be important as a storage reservoir to protect the tRNA from degradation before being recruited to the 30S PIC.

IF3 consists of two domains, the $\mathrm{N}$-terminal (NTD) and C-terminal (CTD), connected by a linker (Figure 2C). The structures of the separate domains are available; however, their arrangement in full-length IF3 is not known. The N-terminal domain of IF3 has a globular $\alpha / \beta$ fold, whereas the IF3-C domain is built of a two-layered $\alpha / \beta$ sandwich (Biou et al., 1995; Garcia et al., 1995). Single-molecule FRET experiments with fluorescence reporter groups introduced in the IF3-NTD and IF3-CTD suggest that free IF3 fluctuates between two conformations, a closed one with the two domains packed against one another and an open conformation with the domains adopting an extended arrangement (D. Rodnin, P. Milon, C. Seidel, M. V. Rodnina, unpublished data). Binding of IF3 to the 30S subunit leads to the stabilization of the open conformation of IF3. The binding site for the factor is located at the platform of the $30 \mathrm{~S}$ subunit (McCutcheon et al., 1999; Dallas \& Noller, 2001; Fabbretti et al., 2007). Hydroxyl radical probing (Dallas \& Noller, 2001), mutational analysis (Tapprich et al., 1989), and a recent cryoEM reconstruction of the 30S IC (Julian et al., 2011) placed IF3-CTD at the 790 loop of 16S rRNA, whereas IF3-NTD was located in the close proximity to fMet-tRNA ${ }^{\mathrm{fMet}}$ (Julian et al., 2011). The functional role of the IF3-NTD and the linker region is not known. IF3 carrying mutations in the NTD and the linker region could bind normally to 30S subunits, but were defective in start codon and fMettRNA $^{\text {fMet }}$ selection (Sussman et al., 1996; Sette et al., 1999; Maar et al., 2008) and in the discrimination against leaderless mRNA (Maar et al., 2008), which suggests a role of the IF3 linker in maintaining initiation fidelity.

IF3 has several functions during translation initiation. It interferes with ribosomal subunit association (Debey et al., 1975), affects the rates of tRNA association to and dissociation from the P site (Gualerzi et al., 1977; Wintermeyer \& Gualerzi, 1983; Antoun et al., 2006a), ensures the fidelity of translation initiation (Hartz et al., 1989; Hartz et al., 1990; Antoun et al., 2006a; Lomakin et al., 2006; Milon et al., 2008) and is crucial for the discrimination against mRNAs with unfavorable TIRs (La Teana et al., 1993; Grigoriadou et al., 2007b; Milon et al., 2008).

\section{Bacterial mRNAs}

Bacterial mRNAs are normally polycistronic and possess characteristic signals for initiation of protein synthesis 
in the TIR which spans nucleotides -20 to +15 around the translation start codon (Dreyfus, 1988). The components of the TIR that are known to affect the initiation efficiency are: (i) the start codon; (ii) the Shine-Dalgarno (SD) sequence which is located approximately 7-10 nucleotides upstream of the initiator codon and pairs with a complementary sequence near the $3^{\prime}$ end of 165 rRNA (anti-Shine-Dalgarno sequence, aSD); (iii) the thermodynamic stability of the mRNA fold near the start site; and (iv) A/U-rich elements in the mRNA which are recognized by protein $\mathrm{S} 1$ of the $30 \mathrm{~S}$ ribosomal subunit. Usually a combination of these elements contributes to the recruitment of an mRNA to the ribosome and thus the overall structure of the TIR can be thought as being an essential element determining the efficiency with which a given mRNA is recruited for translation (Gualerzi et al., 2001; Jin et al., 2006). Although AUG is most commonly used as initiation codon (83\% in E. coli), GUG and UUG are also used rather frequently ( $14 \%$ and $3 \%$, respectively, in E. coli and up to $40 \%$ in other organisms) (Ma et al., 2002). Non-canonical AUU, AUC, CUG initiation codons have been found in infC (encoding IF3) (Polard et al., 1991; Baudet et al., 2010), pcnB (encoding E. coli poly(A) polymerase) (Binns \& Masters, 2002), dnaA (encoding the protein involved in initiation of DNA replication in E. coli and Deinococcus radiodurans) and rpsL (the ribosomal protein S12 in D. radiodurans) (Baudet et al., 2010). Depending on the sequence of the TIR, most of the mRNAs can be classified into one of three main groups, those (i) containing the Shine-Dalgarno sequence (SD-led), (ii) lacking the SD (non-SD-led), and (iii) leaderless mRNAs (Figure 3). In addition, initiation on polycistronic mRNAs can proceed through the re-initiation mechanism (Figure 3). After completion of translation of an upstream open reading frame (ORF) the ribosome can remain bound to the mRNA and slide in a bi-directional manner (see (Yoo \& Rajbhandary, 2008) for references) until an AUG codon is found, usually in close proximity to the preceding termination codon (Yoo \& Rajbhandary, 2008). The mechanism of re-initiation has received little attention in recent years, therefore in the following we focus on the mechanisms of de novo initiation on the leading ORF.

\section{SD-led mRNAs}

Most common (and best studied) are the mRNAs that use the SD sequence, typically GGAGG, in their $5^{\prime}$ untranslated region ( $5^{\prime}$ UTR) to anchor the mRNA on the 30 S subunit through association with the aSD sequence in the 16S rRNA. Sequence analysis of a large number of bacterial genomes suggested that an SD sequence is present in more than $40 \%$ of all genes (Ma et al., 2002). In general, fast-growing bacteria, gram-negative thermophiles, spirochetes, methanogens, and hyperthermophilic archaea have a relatively high proportion of SD-containing genes (up to 90\%), while in obligate intracellular parasites, surface parasites, pathogens, and cyanobacteria this proportion is diminished (to as little as 10-20\%) (Ma et al., 2002; Chang et al., 2006). The spacing between the SD sequence and the initiation codon varies from 5 to 13 bases, with optimal spacing of about 7-10 bases in E. coli mRNAs. The SD-aSD interaction leads to the placement of the initiation codon in the $\mathrm{P}$ site of the ribosome, where it is recognized by fMet-tRNA ${ }^{\mathrm{fMet}}$. The importance of the SD-aSD pairing has been conclusively demonstrated by experiments showing that mRNA translation can be impaired by mutations within the SD sequence and then restored by compensatory mutations in the aSD (Hui \& de Boer, 1987; Jacob et al., 1987). However, overall, the strength of the SD correlates only moderately with the efficiency of translation (Calogero et al., 1988; Melancon et al., 1990; de Smit \& van Duin, 1994; Lee et al., 1996; Ma et al., 2002; Nakamoto, 2006). When expressed at a moderate level (30-40\% of total ribosomes), specialized ribosomes with an altered aSD sequence are only two-fold less active than normal ribosomes for the translation of bulk cellular mRNAs (Skorski et al., 2006). Ribosomes lacking the $3^{\prime}$ end of 16S rRNA (and therefore the aSD sequence) correctly select the translation start site in some natural mRNAs, suggesting that the SD sequence is not the only determinant of the translational initiation (Melancon et al., 1990). Together, these findings suggest that the SD-aSD

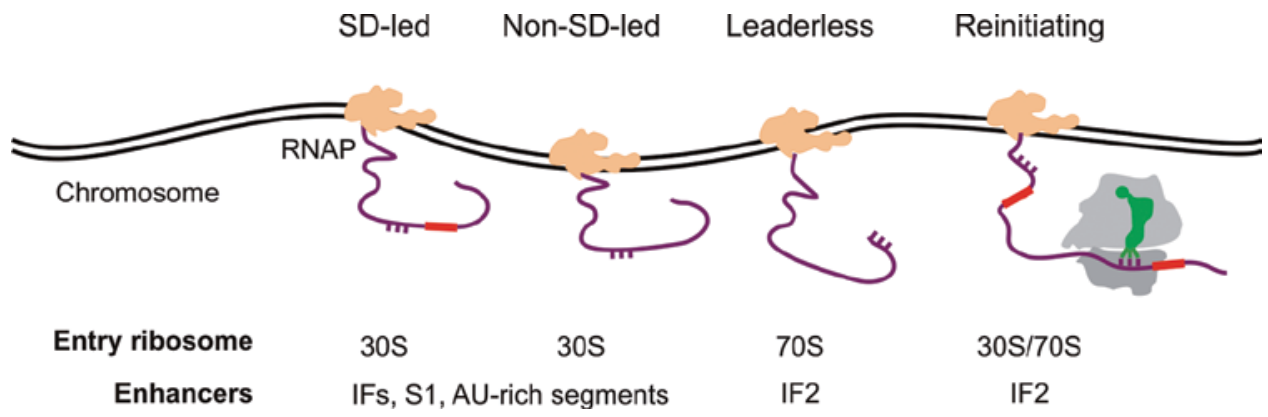

Figure 3. Diversity of initiation mechanisms for bacterial mRNAs. mRNAs emerging from the elongating RNA-polymerase (RNAP) display the TIR for ribosome binding. SD-led and non-SD-led mRNAs are recruited to the 30S subunit. The leaderless mRNA enters translation through the $70 \mathrm{~S}$ ribosome, whereas the state of the ribosome (30S subunit or $70 \mathrm{~S}$ ribosome) acting in mRNA re-initiation is controversial (Yoo \& Rajbhandary, 2008). The potential secondary structure at the TIR (not shown) modulates the efficiency of initiation and may play a particularly important role during translation of mature full-length mRNAs uncoupled to transcription (not shown). (See colour version of this figure online at www.informahealthcare.com/bmg) 
interaction plays an important but not essential role for the synthesis of bulk cellular proteins.

\section{Non-SD-led mRNAs}

mRNAs that lack the SD sequence exist in most bacteria and archaea (Tolstrup et al., 2000; Weiner et al., 2000; Ma et al., 2002; Chang et al., 2006). Genes with an AUG start codon are more likely to have an SD sequence than genes with either GUG or UUG (Ma et al., 2002). In archaea and some bacteria internal genes of operons have a much higher SD presence than those of leading genes (Ma et al., 2002; Chang et al., 2006). Essentially nothing is known about the mechanism of initiation on non-SD-led mRNAs. They are generally less structured in their TIR; in fact, the lack of local RNA secondary structure around the start codon is crucial for the expression of non-SDled reporter gene constructs in bacteria (Scharff et al., 2011). mRNAs lacking the SD sequence bind to the $30 \mathrm{~S}$ subunit rapidly and form a stable complex committed to translation (Milon et al., 2008); however, the mechanisms by which the start codon is found is not clear. AUG itself is an important recognition element. Another potential mediator is protein S1, which may be an important enhancer of mRNA binding of both SD-led and non-SDled mRNAs (see below).

One of the most curious examples of a non-SD-led mRNA in E. coli is rpsA; it codes for the protein S1, which on the ribosome recognizes A/U-rich elements of the mRNA. The TIR of the S1 mRNA shows a number of unusual features. It extends far upstream (to position -91) of the initiator AUG, lacks a canonical SD sequence, and can fold into three successive hairpins that are essential for its high translational activity (Boni et al., 1991; Skorski et al., 2006). Interestingly, the efficiency of rpsA translation is strongly repressed by free $\mathrm{S} 1$, suggesting a mechanism of translation autoregulation (Boni et al., 1991).

\section{Leaderless mRNAs}

Leaderless genes that lack their 5' UTR are widespread in a variety of bacteria, e.g. in Actinobacteria, Deinococcus, and Thermus more than $20 \%$ of genes are leaderless (Zheng et al., 2011). Leaderless mRNAs have a very short or no 5'-UTR and directly bind to $70 \mathrm{~S}$ ribosomes, recruiting fMet-tRNA ${ }^{\text {fMet }}$ to the AUG codon with the help of IF2 (Grill et al., 2000). Close proximity of the start codon to the $5^{\prime}$ terminus is a strong determinant of both ribosome binding and expression (Krishnan et al., 2010). Curiously, translation of leaderless mRNAs requires the AUG codon as initiation signal, in addition to the codon-anticodon complementarity (Van Etten \& Janssen, 1998). $30 \mathrm{~S}$ proteins S1 and S2, which modulate the recruitment of leader-containing mRNA, are dispensable for the translation of leaderless RNA (Moll et al., 2002). Moreover, a number of other ribosomal proteins are also dispensable: S6, S12, S18, and S21 (Kaberdina et al., 2009).

Notably, leaderless mRNAs may have an important role in stress adaptation in bacteria and may be much more widespread than previously thought. Recently, a stress-induced endo-ribonuclease activity of an $E$. coli toxin, MazF, was reported to cleave single-stranded mRNAs at ACA sequences closely upstream of the AUG start codon of some specific mRNAs, thereby generating leaderless mRNAs (Vesper et al., 2011). Furthermore, MazF also targets $16 \mathrm{~S}$ rRNA, removing the sSD sequence from the $3^{\prime}$ terminus. This produces a subpopulation of ribosomes that selectively translate leaderless mRNAs under conditions of stress (Vesper et al., 2011). Two reports pointed out that translation of mRNAs with and without a leader sequence responds differently to temperature changes (Grill et al., 2002; Vimberg et al., 2007), further linking the type of mRNA entry to the adaptation to environment changes.

\section{Assembly of the 30S PIC}

\section{Recruitment of initiation factors and fMet-tRNA ${ }^{\text {fMet }}$}

In the first phase of translation initiation, initiation factors, fMet-tRNA ${ }^{\mathrm{fMet}}$, and mRNA are recruited to the 30S subunit. Early work showed that initiation factors can interact with the $30 \mathrm{~S}$ subunit independent of each other, suggesting a random order of binding with a number of potential alternative pathways towards 30S PIC assembly (Gualerzi \& Pon, 1990). However, recent kinetic data revealed that the arrival times of the three initiation factors and fMet-tRNA to the 30S subunit are quite different, about $30 \mathrm{~ms}$ for IF1, $1.3 \mathrm{~ms}$ for IF2, <1 ms for IF3, and $100 \mathrm{~ms}$ for fMet-tRNA ${ }^{\mathrm{fMet}}$, suggesting a kinetically favored route of the 30S PIC assembly (Figure 4A) (Milon et al., 2012). The arrival times imply that IF3 and IF2 are the first factors to bind to the 30S subunit, followed by IF1, which binds significantly more slowly, and finally by fMet-tRNA ${ }^{\text {fMet }}$, which docks to IF2 bound to the $30 \mathrm{~S}$ subunit (Milon et al., 2010). The early intermediate of the 30S PIC assembly, the 30S-IF2.IF3 complex, is formed very rapidly but is rather short-lived (lifetime of about 30 ms; (Milon et al., 2012)). The following recruitment of IF1 leads to a strong stabilization of IF2 and IF3 in the 30S PIC, with the residence times of the factors up to 1500fold longer than in the initial complex. Docking of fMettRNA $^{\mathrm{fMet}}$ is the slowest reaction in the 30S PIC assembly. This final assembly step may be delayed even further (by up to $25 \mathrm{~ms}$ ) when fMet-tRNA ${ }^{\mathrm{fMet}}$ is stored in the complex with IF2·GTP (Milon et al., 2010).

Translation initiation is tightly coupled to ribosome recycling, which replenishes the pool of ribosomal subunits available for initiation. In this case, the predominant pathway of the 30S PIC formation is somewhat different from the one prevailing with free ribosomal subunits (Figure 4B). After the termination of mRNA translation, the $70 \mathrm{~S}$ post-termination complexes are split into 30S.mRNA.tRNA complexes and 50S subunits by the concerted action of RRF and EF-G (Karimi et al., 1999; Peske et al., 2005). Re-association of the subunits is prevented by IF3 binding to the 30S complex (Debey et al., 1975). Kinetically, the recruitment of IF3 is limited by the rate of the subunit splitting by EF-G and RRF, which is 
A

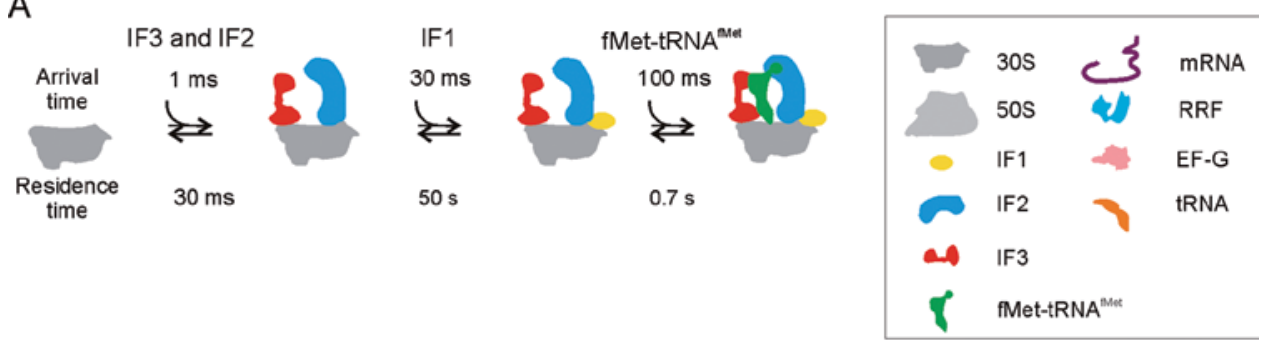

B

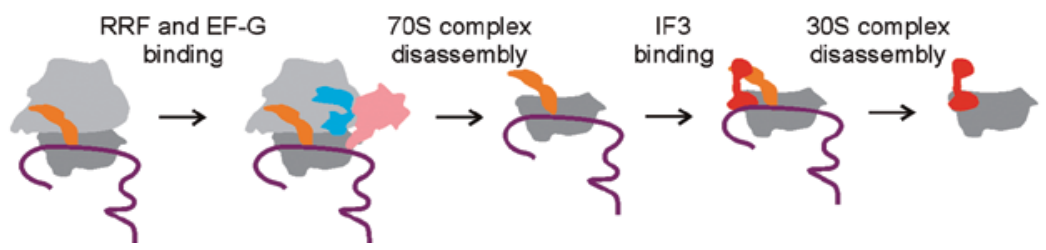

Figure 4. Elemental steps of 30S PIC assembly. (A) Assembly on vacant 30S subunits. The kinetically favored order of initiation factors and fMet-tRNA $^{\mathrm{fMet}}$ arrivals and the residence times of the respective complexes are indicated. (B) Assembly of 30S PIC coupled to ribosome recycling. (See colour version of this figure online at www.informahealthcare.com/bmg)

slow. However, after the ejection of the 50S subunit, IF3 can bind to the 30S.mRNA.tRNA complex with the same rate as to vacant ribosomes (Milon et al., 2012). Binding of other initiation components, particularly of fMet-tRNA and the new mRNA, may be delayed until deacylated tRNA and the translated mRNA have been released from the 30 S subunit, which is promoted by IF3 (Karimi et al., 1999; Peske et al., 2005).

The 30S PIC formation provides an important checkpoint for fMet-tRNA ${ }^{\text {fMet }}$ selection. 30S-bound IF2 specifically recognizes fMet-tRNA ${ }^{\mathrm{fMet}}$ and favors kinetically the binding of aminoacyl-tRNAs that have the $\alpha_{N_{2}}$ group blocked more than it does with non-blocked elongator tRNAs (Canonaco et al., 1986; Gualerzi \& Wintermeyer, 1986; Boelens \& Gualerzi, 2002; Antoun et al., 2006a). A unique feature of initiator tRNA ${ }^{\mathrm{fMet}}$ is a mismatch at the bottom of the acceptor stem (C1-A72). When the activity of formyl-methionyl-transferase is impaired, non-formylated Met-tRNA ${ }^{\mathrm{fMet}}$, as well as elongator aa-tRNAs, can be recruited to the 30S PIC, albeit very slowly (Antoun et al., 2006a; Pavlov et al., 2011), probably because interactions with IF2 are lacking or impaired.

\section{Maturation of the 30S PIC}

The initial recruitment of initiation factors to the $30 \mathrm{~S}$ subunit is followed by conformational rearrangements which collectively can be referred to as 30S PIC maturation. Some of the rearrangements depend on the synergistic action of initiation factors, in particular IF1 and IF3, and are essential for the ability of the ribosome to discriminate against non-optimal TIRs and a non-cognate start codon during the following steps of initiation (La Teana et al., 1993; Grigoriadou et al., 2007b; Milon et al., 2008). Cryo-EM structures indicated that IF3 induces a rearrangement within the $30 \mathrm{~S}$ subunit towards the conformation that is usually observed in the rotated form of the $70 \mathrm{~S}$ ribosome, i.e. with the $30 \mathrm{~S}$ head tilted towards the platform (Julian et al., 2011), whereas in the absence of IF3 a classic, non-rotated structure of the 30S subunit is found (Simonetti et al., 2008). The importance of the dynamics of the $30 \mathrm{~S}$ subunit is further supported by the mutational analysis of $16 \mathrm{~S}$ rRNA which identified a number of mutations in the neck of the $30 \mathrm{~S}$ subunit and in the vicinity of the conserved A1413:G1487 base pair of h44 that affected the initiation fidelity (Qin \& Fredrick, 2009). Crystal structures showed that IF1 promotes the displacement of one strand of h44 disrupting the A1413:G1487 base pair (Carter et al., 2001), suggesting an active role for IF1 in modulating the 30S subunit conformation by remodeling the 16S rRNA. More recently, structural probing of 30S subunits showed that the 1408 region of h44 changed the conformation upon IF1 binding, whereas formation of the correct codon-anticodon interaction reverted the observed effect (Qin et al., 2012). Furthermore, interfering with the conformational mobility of the $30 \mathrm{~S}$ subunit by adding the antibiotic streptomycin or omitting IF1 decreased the fidelity of initiation during subunit joining (Milon et al., 2008).

Further rearrangements that occur upon maturation of the 30S PIC appear to involve conformational adjustments of IF2. The comparison of cryo-EM structures of the 30S IC with and without IF3 indicated that the CTD of IF2 may be positioned in a different way, depending on the presence of IF3 (Simonetti et al., 2008; Julian et al., 2011). Kinetic experiments also indicated IF2 rearrangements (Grigoriadou et al., 2007a), although the correspondence between the fluorescence changes of IF2 observed in that work and the rearrangements observed in cryo-EM (Myasnikov et al., 2005) is not clear. Recent NMR studies on isolated IF2 domains suggested that the C2 subdomain has an intrinsic high mobility which may be independent of the G2 conformation (Wienk et al., 2012). Together, the data suggest the propensity of IF2 CTD to move, presumably, in order to optimize the alignment of the fMet-tRNA ${ }^{\mathrm{fMet}}$ with respect to the AUG codon and to the incoming 50 S subunit. 


\section{Recruitment of mRNA}

The timing and stability of mRNA binding to the $30 \mathrm{~S}$ PIC prior to start codon selection is independent of the composition of the $30 \mathrm{~S}$ complex, i.e. the presence of the initiation factors and fMet-tRNA ${ }^{\mathrm{fMet}}$ (Studer \& Joseph, 2006; Milon et al., 2012). The initial recruitment of mRNA to the $30 \mathrm{~S}$ subunit is modulated by four parameters: (i) the abundance of a given mRNA in the total mRNA pool (Passalacqua et al., 2009); (ii) the secondary structure of the TIR (de Smit \& van Duin, 1994; Studer \& Joseph, 2006); (iii) the presence of an SD sequence, the strength of the SD-aSD complex, and the length of the linker between the SD sequence and the start codon; and (iv) the accessibility of single-stranded A/U sequences that can bind to the protein S1 (Komarova et al., 2002; Skorski et al., 2006). These factors determine whether a particular mRNA docks to the ribosome prior to, simultaneously with, or subsequently to the arrival of IFs and fMet-tRNA ${ }^{\text {fMet }}$. Concentrations of mRNAs in the cell may vary by orders of magnitude, and not all mRNAs are expressed in all cells in a bacterial population at a given time (Passalacqua et al., 2009). Variations in the mRNA secondary structures range from weakly folded mRNAs to compact, tightly regulated riboswitches (Geissmann et al., 2009).

Secondary structure at the TIR of mRNAs has been long recognized to have a strong influence on protein expression by hampering mRNA loading onto the ribosome (Nakamoto, 2006). Base exchanges in the TIR and manipulation of its $\mathrm{G}+\mathrm{C}$ content have a profound effect on translational efficiency, indicating that mRNA secondary structure in this region impairs translation (Voges et al., 2004). Bioinformatic analysis indicated that mRNA secondary structure content is particularly low at the beginning of genes in E. coli and Salmonella typhimurium (Katz \& Burge, 2003; Tuller et al., 2010). The notion that there is a selection for structures with weak folding at the beginning of genes has been supported by several studies (Kudla et al., 2009; Allert et al., 2010; Tuller et al., 2010); however, the implications of this finding for gene expression remained controversial. mRNA folding and the associated rates of translation initiation were suggested to play a predominant role in shaping expression levels of individual genes (Kudla et al., 2009; Allert et al., 2010). In contrast, other studies indicated that the selection for weak secondary structures at the TIR is global and not related to protein abundance or mRNA levels (Tuller et al., 2010).

Although weak secondary structure at the TIR favors efficient initiation (Kudla et al., 2009), most of the mRNAs in the cell are probably folded to some extent. Furthermore, also highly structured mRNAs can be recruited to the ribosome. Structural work suggested the existence of a docking site for folded mRNAs at the platform of the $30 \mathrm{~S}$ subunit in the close proximity of proteins S2, S7, S11, S18, and S21 (Allen et al., 2005; Jenner et al., 2005; Marzi et al., 2007). The proteins provide patches of positive charges which might bind different folded mRNAs regardless of their sequence (Marzi et al., 2007). Notably, also poly(A) and poly(U) extensions $5^{\prime}$ to the coding region of mRNAs formed stable contacts to protein S2 (Yusupova et al., 2006), suggesting that also unfolded mRNAs can bind to the same region. One can speculate that these proteins, together with S1 (see below), which is located in the vicinity, form a universal initial docking site for all mRNAs, although the details of recruitment may be different depending on the features of the mRNA (Figure 5A).

Many mRNAs possess an A/U-rich region $5^{\prime}$ of the start codon and the SD region (if present). A/U-rich sequences are recognized by protein S1 (Komarova et al., 2002), which is present in many, albeit not all, bacteria. S1 might facilitate the initial docking of mRNAs or assist mRNA unfolding by entrapping melted single-stranded regions. Cryo-EM structures provided evidence for direct interactions of S1 with 11 nucleotides of the mRNA immediately upstream of the SD sequence (Sengupta et al., 2001). The location of $\mathrm{S} 1$ at the platform of the 30S subunit suggests that S1 may constitute a part of the stand-by site for mRNA recruitment (Sengupta et al., 2001; Marzi et al., 2007) (Figure 5B). In fact, mRNA selection was found to be dominated by S1, rather than by the SD-aSD interaction (Ringquist et al., 1995). SD and A/U-rich enhancer stimulate translation co-operatively: initiation on strong SD sequences is stimulated by the enhancer much more than on weak SD sequences (Vimberg et al., 2007). Disruption of the E. coli gene coding for S1 is lethal (Kitakawa \& Isono, 1982). A decreased level of
A

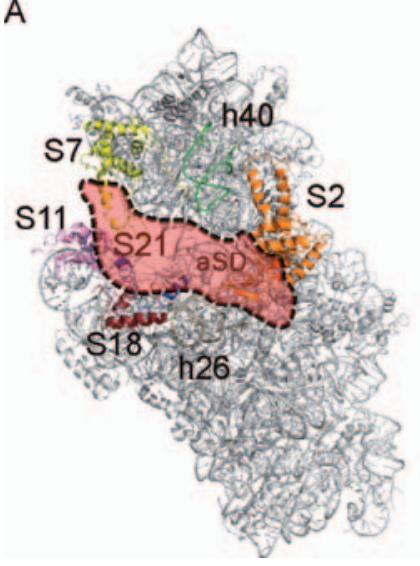

B

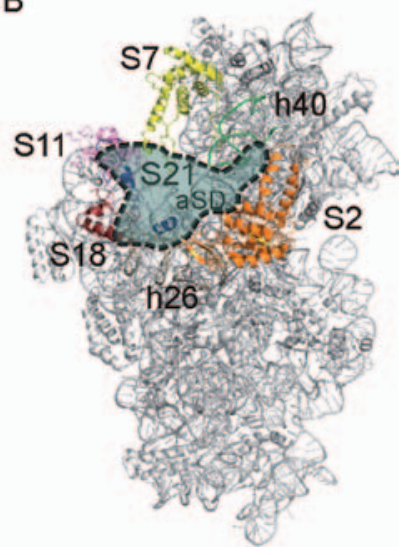

Figure 5. The mRNA docking site at the platform of the $30 \mathrm{~S}$ subunit. (A) The location of the universal mRNA docking site (semitransparent salmon) as suggested by cryo-EM (adapted from (Marzi et al., 2007)). Indicated are the positions of the aSD region, of the proteins S2 (orange), S7 (yellow), S11 (pink), S18 (brown), and S21 (magenta), and h26 (sand) and h40 (green) of 16S rRNA. (B) The location of protein S1 suggested by cryo-EM. The position of S1 bound to 11 nucleotides immediately upstream of the SD sequence of the mRNA is indicated semitransparent light teal (redrawn from (Sengupta et al., 2001) using the structure of the 30 S subunit from E. coli, PDB 2AW7; (Schuwirth et al., 2005)). Note the different orientations of the $30 \mathrm{~S}$ subunit in A and B. (See colour version of this figure online at www.informahealthcare. $\mathrm{com} / \mathrm{bmg}$ ) 
S1 protein in the cell leads to a rapid decrease in total protein synthesis (Sorensen et al., 1998), which may suggest a crucial role of $\mathrm{S} 1$ in translation initiation.

The initial recruitment of mRNA to the $30 \mathrm{~S}$ subunit is followed by conformational adjustments which depend on the properties of the TIR. A structured mRNA attached at the docking platform of the 30S subunit has to unfold, which would expose the SD sequence and the start codon (Marzi et al., 2007). Weak secondary structure elements are likely to fluctuate spontaneously between the folded and unfolded state; the latter may be trapped by the ribosome (de Smit \& van Duin, 1994; Studer \& Joseph, 2006). The SD-aSD interaction positions the mRNA in such a way that the start codon is placed in the $\mathrm{P}$ site ready to interact with the anticodon of fMet-tRNA ${ }^{\text {fMet }}$. The final adjustment may require movements of the mRNA from the stand-by to the initiation site (Canonaco et al., 1989; La Teana et al., 1995; Studer \& Joseph, 2006; Yusupova et al., 2006). The efficiency of unfolding can be mediated by ligands and environmental conditions (metabolites, proteins, non-coding RNA, thermoswitches) by a variety of potential mechanisms, such as entrapment of inactive mRNA folds by the ribosome or competition between a trans-acting ligand and the $30 \mathrm{~S}$ subunit for binding to the mRNA (Geissmann et al., 2009).

\section{Transition to the 30 S IC}

\section{Start codon selection}

The major rearrangement that converts the 30S PIC into the mature 30S IC is the start codon recognition by the anticodon of fMet-tRNA ${ }^{\mathrm{fMet}}$. In the SD-led mRNAs, formation of the SD-aSD complex is expected to be sufficient to bring the start codon into the $\mathrm{P}$ site (Gold, 1988). However, as the length of the spacer varies considerably, sense codons on either side of the start codon may become accessible for IF2-mediated recruitment of fMet-tRNA ${ }^{\mathrm{fMet}}$ to a near-cognate codon or for elongator tRNA binding (Gold, 1988; Hartz et al., 1989; Antoun et al., 2006a). Both scenarios can lead to synthesis of a protein with an aberrant $\mathrm{N}$-terminal amino acid sequence or to out-of-frame mRNA reading. However, in reality the SD-aSD pairing is not essential for the selection of the reading frame (Calogero et al., 1988) and the error frequency of initiation is very low, indicating that the ribosome controls the quality of codon-anticodon interaction and reject poor initiation substrates. Initiation on near-cognate codons (i.e. those that are not fully complementary to the anticodon of initiator tRNA, such as CUG, AUU, AUA, or AUC) by fMet-tRNA ${ }^{\mathrm{fMet}}$ is $100-1000$ times less frequent than on AUG, even if those codons are placed in an mRNA context that is optimal for initiation (O'Connor et al., 1997; O'Connor et al., 2001; Qin et al., 2007). Erroneous initiation at internal GUG or UUG codons, which are used as initiation codons, may occur at a somewhat higher frequency of (1-6) $\times 10^{-2}$; initiation at other internal codons is negligible ( $\mathrm{O}^{\prime}$ Connor et al., 2001).
Initiation factors play an important role in tuning the fidelity of start codon recognition (Hartz et al., 1989; Hartz et al., 1990; Petrelli et al., 2001; Antoun et al., 2006a). Binding of IF3 to the ribosome increases the rate of association and dissociation of any tRNA by several orders of magnitude, and this effect is amplified by IF1 (Wintermeyer \&Gualerzi, 1983; Antoun et al., 2006a). This ensures that incorrect tRNAs are rapidly rejected from the complex and can be replaced by the correct initiator tRNA. The latter may be specifically stabilized through the three adjacent G-C base pairs in the anticodon stem, which is a characteristic feature of initiator tRNA (Seong \& Rajbhandary, 1987; Mandal et al., 1996; Lancaster \& Noller, 2005). Two of these G-C base pairs (G29-C41 and G30-C40) are particularly important for efficient initiation, and interact with 16S rRNA residues G1338 and A1339, respectively (Mandal et al., 1996; Qin et al., 2007). Correct start codon recognition results in a major stabilization of fMet-tRNA ${ }^{\mathrm{fMet}}$, IF2, and IF1 binding to the 30S subunit, whereas the binding of IF3 is destabilized (Milon et al., 2008; Milon et al., 2012). The affinity switch induced by codon recognition comprises an important checkpoint that prepares the 30S IC for the following transition to the 70S IC and commits the mRNA for translation (Milon et al., 2008; Milon et al., 2012).

\section{Structure of the 30S IC}

The structure of the mature 30S IC with all components in place has been recently revealed by cryo-EM studies (Julian et al., 2011) (Figure 6A). As mentioned above, in the 30S IC the head of the 30S subunit was found in a rotated conformation with respect to the body (Figure 6B). Taking into account the position of the SD-aSD duplex, the rotation of the $30 \mathrm{~S}$ subunit head moves the mRNA in the direction which would place the start codon closer to the P site. This finding agrees well with crosslinking studies which suggested that the formation of the SD-aSD complex in the absence of initiation factors places the mRNA in a "standby" position, from which it is shifted backward, i.e. closer to the P site, before the large subunit joins the complex (La Teana et al., 1995). Similarly, crystal structures of the 70S IC indicate that the mRNA has moved in the $3^{\prime} \rightarrow 5^{\prime}$ direction with simultaneous clockwise rotation and lengthening of the SD duplex, bringing it into contact with ribosomal protein S2 (Yusupova et al., 2006). The conformation of the 30S subunit in the 30S IC is the same as in the 70S IC, both stalled in the presence of IF2.GDPNP, where the 30S subunit is also found in a rotated orientation with respect to the $50 \mathrm{~S}$ subunit (Allen et al., 2005). Notably, the conformation is not induced by the 50S subunit and does not occur in the absence of IF3 (Simonetti et al., 2008). This suggests that binding of IFs, in particular IF3, could induce or stabilize the altered 30S subunit conformation (Julian et al., 2011). The rotated state of the $30 \mathrm{~S}$ subunit appears to be retained upon 50S subunit joining until GTP hydrolysis and dissociation of IF2 (Marshall et al., 2009). 
A

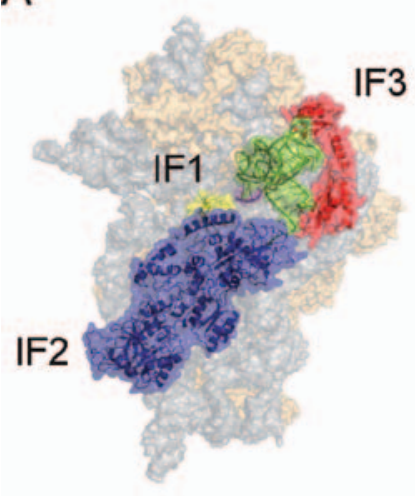

B

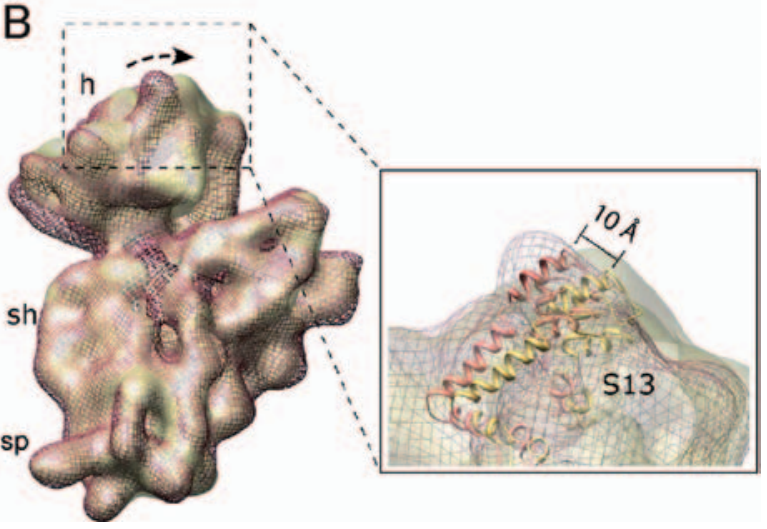

Figure 6. Structure of the 30S IC. (A). Cryo-EM reconstruction of a complete 30S IC with IF1 (yellow), IF2 (blue), IF3 (red) and fMet-tRNA ${ }^{\mathrm{fMet}}$ (green) bound to the 30S subunit (16S rRNA, gray; ribosomal proteins, sand). (B) 30S subunit conformations in the complex with mRNA in the absence of initiation factors or tRNA (red mesh) and in 30S IC (semitransparent yellow). The arrow indicates the clockwise rotation of the 30S subunit head. The inset shows the positions of protein S13 in the two maps for comparison (reproduced from (Julian et al., 2011) with permission). (See colour version of this figure online at www.informahealthcare.com/bmg)

In the 30S IC, fMet-tRNA ${ }^{\mathrm{fMet}}$ is held in its characteristic position by two interactions: one involving the anticodon stem which is buried in the P site of the 30 S subunit, and the other between IF2 and the acceptor end of the tRNA (Simonetti et al., 2008; Julian et al., 2011). The orientation of fMet-tRNA ${ }^{\mathrm{fMet}}$ in the known structures of initiation complexes deviates from the canonical $\mathrm{P}$ site position and is referred to as a $\mathrm{P} / \mathrm{I}$ state (Allen et al., 2005). However, the details of the fMet-tRNA ${ }^{\mathrm{fMet}}$ orientation are not identical in the available 30S IC and $70 \mathrm{~S}$ IC structures; the differences may be related to various functional states of the complexes (30S IC with or without IF3, 30S IC vs. 70S IC). In all structures, the anticodon stem of the tRNA is buried in the P site of the 30S subunit, whereas the position of the tRNA CCA end varies. In the 30S IC from E. coli prepared with the full set of initiation factors and the non-hydrolyzable GTP analog, GDPNP, the CCA end points towards the A site of the peptidyl transferase center (Julian et al., 2011). A somewhat different $\mathrm{P} / \mathrm{I}$ state was reported for the 30S IC from T. thermophilus formed with GTP in the absence of IF3 (Simonetti et al., 2008), which may reflect the known effect of IF3 on the stability of fMet-tRNA ${ }^{\text {fMet }}$ binding to the 30S IC. Comparison of the 30S IC with the 70S IC from E. coli (both with GDPNP) suggested that, upon binding of the 50S subunit, the CCA end moves towards the E site (70S IC; (Allen et al., 2005)). The position of the C2 domain of IF2, to which the fMet moiety of fMettRNA $^{\mathrm{fMet}}$ is bound, changes accordingly. It is possible that all described $\mathrm{P} / \mathrm{I}$ positions are sampled during the transition of the initiator tRNA towards the final P-sitebound state and that they are important for discrimination of mRNAs with unfavorable TIR.

\section{Formation of the 70S IC}

\section{The sequence of events}

The formation of the 70S IC is the final, quite complex step of initiation which commits an mRNA for translation (Figure 7). The 50S subunit binds to the $30 \mathrm{~S}$ IC carrying all three initiation factors, mRNA, and fMettRNA $^{\text {fMet }}$ (Grigoriadou et al., 2007a; Milon et al., 2008). The ribosome-bound IF2, together with fMet-tRNA ${ }^{\text {fMet }}$ attached to its C2 domain, provide a large surface area for the docking of the 50S subunit. Interestingly, rapid subunit association depends on a specific interaction between IF2 and the protein L12 of the 50S subunit (Huang et al., 2010; Mandava et al., 2012). Association of the 50S subunit triggers GTP hydrolysis by IF2 (Tomsic et al., 2000; Grigoriadou et al., 2007a; Huang et al., 2010) and the release of IF3 and IF1 from the complex (Milon et al., 2008). IF3 seems to prevent the accommodation of fMet-tRNA ${ }^{\mathrm{fMet}}$ in the $\mathrm{P}$ site (Allen et al., 2005) and slows down 50S subunit joining (Antoun et al., 2006a; Milon et al., 2008), but is required to control the efficiency and fidelity of initiation on a given mRNA (Milon et al., 2008).

GTP hydrolysis and conformational change from the GTP-bound to the GDP-bound form of IF2 involves substantial rearrangements of the factor (Roll-Mecak et al., 2000) and the entire ribosome. In the presence of a non-hydrolyzable GTP analog, IF2 interacts mostly with the 30S subunit and extends to fMet-tRNA ${ }^{\mathrm{fMet}}$, whereas in the GDP-bound state the factor moves away from the tRNA, loses -part of the interactions with both ribosomal subunits and adopts a "ready-to-leave" conformation (Myasnikov et al., 2005). Furthermore, GTP hydrolysis facilitates the rearrangement that promotes the transition of the ribosome from the rotated to the non-rotated state (Myasnikov et al., 2005; Marshall et al., 2009). Dissociation of IF2 is the final step of complex maturation resulting in the 70S IC complex that is committed to translation.

Joining of the 50S subunit with the 30S IC may itself be a stepwise process (Grigoriadou et al., 2007a; Fabbretti et al., 2007; Milon et al., 2008). The stepwise nature of docking explains how the 50S subunit can bind to the 30S IC while IF3 is still present, even though the factor 


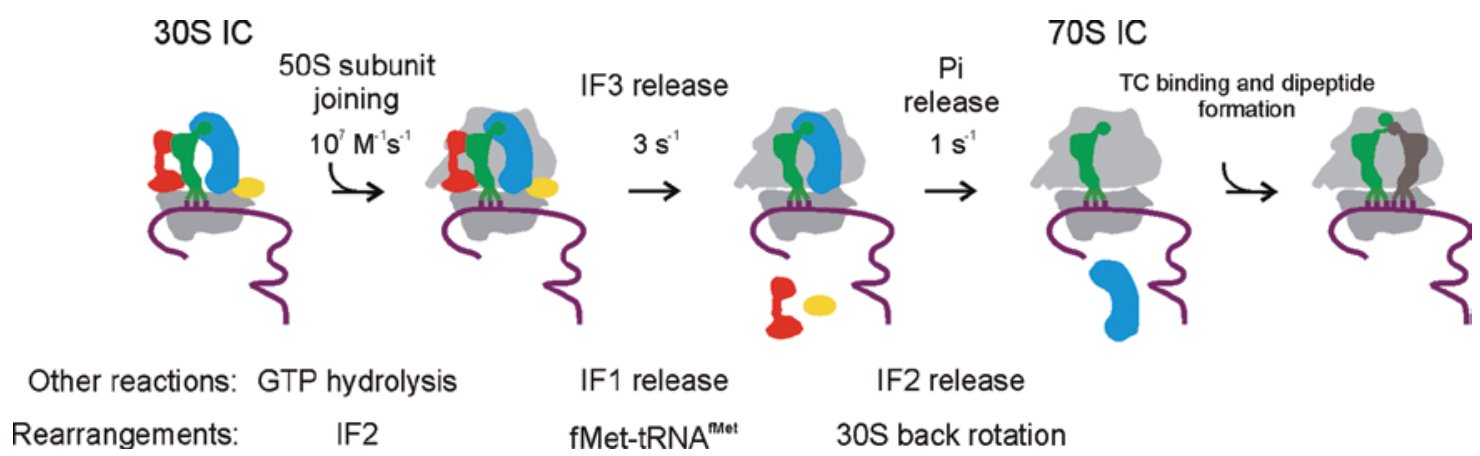

Figure 7. Formation of the 70S IC. Step 1, docking of the 50S subunit to the 30S IC containing all three initiation factors (Milon et al., 2008). Joining of the 50S subunit triggers GTP hydrolysis by IF2, which promotes conformational rearrangements of the factor (Tomsic et al., 2000; Grigoriadou et al., 2007a). Step 2, dissociation of IF3 and IF1 (Milon et al., 2008). The position of fMet-tRNA ${ }^{\mathrm{fMet}}$ likely changes (Allen et al., 2005; Myasnikov et al., 2005; Grigoriadou et al., 2007a; Julian et al., 2011). Step 3, release of Pi from IF2 (Tomsic et al., 2000; Grigoriadou et al., 2007a), dissociation of IF2, and the rearrangements of the 30S subunit from the rotated to non-rotated state (Marshall et al., 2009), resulting in a mature 70S IC. The final step, binding of the ternary complex (TC) EF-Tu•GTP•aminoacyl-tRNA is followed by the formation of the first peptide bond, completing the transition from initiation to elongation. The reaction rate constants are given for an mRNA which forms a moderate-strength SD-aSD interaction and has an optimal spacer between the SD sequence and the AUG codon, which is representative for many E. coli mRNAs (Tomsic et al., 2000; Grigoriadou et al., 2007a; Milon et al., 2008). Alterations in the strength of the SD-aSD complex, the length of the spacer or the identity of the start codon affect (usually reduce) the arrival time of the 50S subunit (Grigoriadou et al., 2007b; Milon et al., 2008). (See colour version of this figure online at www.informahealthcare.com/bmg)

interferes with the formation of an important intersubunit bridge (McCutcheon et al., 1999; Dallas \& Noller, 2001; Julian et al., 2011). Results of time-resolved chemical probing indicate that (i) different interface regions of the ribosomal subunits associate sequentially (Hennelly et al., 2005); (ii) subunit joining entails intermediate stages in which the interactions between IF3 and the ribosome are only partly dissolved; and (iii) the adjustment of the ribosomal subunits precedes the final ejection of IF3 (Fabbretti et al., 2007). Alternatively, based on indirect estimations, Antoun et al. suggested that the binding of fMet-tRNA ${ }^{\mathrm{fMet}}$ to the $30 \mathrm{~S}$ PIC causes the release of IF3 which, in turn, is required for subunit docking (Antoun et al., 2006b). However, direct measurements of IF3 release indicate that binding of fMet-tRNA ${ }^{\text {fMet }}$ to the 30S IC does not necessarily cause the dissociation of IF3 (Milon et al., 2008). Upon binding of fMet-tRNA ${ }^{\mathrm{fMet}}$ to a cognate start codon the affinity of IF3 for the complex decreases radically; however, the factor's residual affinity for the 30S IC (in the range of $10 \mathrm{nM}$ ) is still high enough, such that at the cellular concentrations, the factor remains attached to the $30 \mathrm{~S}$ subunit. However, the $50 \mathrm{~S}$ subunit, once docked, prevents IF3 from rebinding at the interface side of the 30S subunit (McCutcheon et al., 1999; Dallas \& Noller, 2001), rendering the release of the factor practically irreversible (Milon et al., 2008).

\section{Role of the GTP-bound form of IF2 and of GTP hydrolysis}

GTP binding and hydrolysis have a global effect on initiation, even though the effects on each step alone may not be large. The affinity of IF2 binding to the 30 S subunit is 10-fold higher with GTP than with GDP (Pon et al., 1985). Also the affinity of GTP (but not of GDP) to IF2 increased about 10-fold upon binding to the 30S IC, especially in the presence of mRNA and fMet-tRNA ${ }^{\mathrm{fMet}}$ (Antoun et al.,
2003). It was argued that if fMet-tRNA ${ }^{\mathrm{fMet}}$ stabilizes GTP binding to IF2 in the 30S IC, then the binding of initiator tRNA must be stabilized as well (Antoun et al., 2003); hence the important role of the GTP-bound form of IF2 in fMet-tRNA ${ }^{\mathrm{fMet}}$ recruitment. IF2 in complex with GTP or a non-cleavable GTP analogue was shown to promote rapid association of the 50S subunit (Antoun et al., 2003; Grigoriadou et al., 2007a), whereas with GDP subunit joining was slower by about 50 -fold (Antoun et al., 2003). Notably, the sensitivity to GTP is relaxed in IF2 mutants that have a reduced selectivity against unformylated Met-tRNA $^{\mathrm{fMet}}$ (Zorzet et al., 2010; Pavlov et al., 2011). This finding suggests that both the nucleotide bound to IF2 and fMet-tRNA ${ }^{\mathrm{fMet}}$ contribute to conformational remodeling of the structural landscape that is required for $50 \mathrm{~S}$ subunit docking. The transition from the GTP- to the GDP-bound form of the factor after Pi release promotes conformational rearrangements of IF2 and fMet-tRNA ${ }^{\mathrm{fMet}}$ (see above), the dissociation of IF2 (Myasnikov et al., 2005; Grigoriadou et al., 2007a), and the rearrangement of the reverse rotation of the ribosomal subunits, thereby enabling the complex to progress towards elongation (Marshall et al., 2009).

In addition to GTP and GDP, IF2 can also bind guanosine $3^{\prime}, 5^{\prime}$-(bis) diphosphate (ppGpp), an alarmone involved in the stringent response in bacteria (Milon et al., 2006; Mitkevich et al., 2010). In cells growing under optimal conditions, the GTP concentration is high, and that of ppGpp very low. However, under stress conditions, the GTP concentration may decline by as much as $50 \%$, and that of ppGpp can attain levels comparable to those of GTP. Binding of ppGpp to IF2 impairs all IF2 functions and blocks initiation of translation. Thus, IF2 has the properties of a cellular metabolic sensor that oscillates between an active GTP-bound form under conditions that allow active protein synthesis and an inactive 
ppGpp-bound form when shortage of nutrients would be detrimental if not accompanied by a global decrease in translation initiation (Milon et al., 2006).

\section{Kinetic partitioning model for the mRNA recruitment in translation}

Recent kinetic and structural work provides a detailed framework for understanding the mechanisms of mRNA and fMet-tRNA ${ }^{\text {fMet }}$ selection during initiation. Initial mRNA docking to the $30 \mathrm{~S}$ ribosomal subunit depends on the abundance of the mRNA in the cell. Furthermore, for different mRNAs the rates of the initial encounter with $30 \mathrm{~S}$ subunit seem to vary up to 20 -fold, mainly determined by the presence of secondary structure elements in the mRNA ( $\mathrm{k}_{1}$ in Figure 8; (Studer \& Joseph, 2006; Milon et al., 2012)). Notably, other features of the TIR, such as the strength of the SD-aSD interaction or the presence of AUG as start codon are not monitored at this stage (Figure 8, checkpoint 1). Recruitment of structured mRNAs to the stand-by site at the platform of the 30S subunit (Yusupova et al., 2006; Marzi et al., 2007) is followed by unfolding of secondary structure elements and accommodation of the mRNA in the mRNA channel of the $30 \mathrm{~S}$ subunit. The fate of an mRNA at this point depends on kinetic partitioning between mRNA dissociation ( $\mathrm{k}_{-1}$ in Figure 8$)$ and unfolding $\left(\mathrm{k}_{2}\right.$; checkpoint 2): an mRNA with strong secondary structure elements which unfold slowly is more likely to dissociate from the 30S PIC and be replaced by a different mRNA than to enter the 30S IC (Studer \& Joseph, 2006). The recruitment of the correct initiator tRNA, rather than of an incorrect elongator tRNA or non-formylated Met-tRNA ${ }^{\mathrm{fMet}}$, to the 30S PIC is mostly based on specific interactions between fMet-tRNA ${ }^{\text {tMet }}$ and IF2. The following start codon selection operates the affinity switch that leads to locking of the mRNA and fMet-tRNA $^{\mathrm{fMet}}$ on the $30 \mathrm{~S}$ subunit. This comprises the next checkpoint for mRNA selection which favors the mRNAs that have a canonical start codon efficiently recognized by fMet-tRNA ${ }^{\mathrm{fMet}}$ (high $\mathrm{k}_{3}$ value) and disfavors the mRNAs with non-initiation codons (low $\mathrm{k}_{3}$ value) by delaying the transition towards the active 70S IC (checkpoint 3). IF1 and IF3 play a crucial role at this step by stabilizing IF2 (IF1), destabilizing the binding of tRNA (IF3), and modulating the conformation of the 30S subunit (IF1 and IF3). Finally, the transition from the 30S IC to the 70S IC provides the final checkpoint for the mRNA and tRNA selection which monitors the details of the SD-aSD interaction and the presence of the cognate mRNA-tRNA pairs (checkpoint 4) (Antoun et al., 2006a; Milon et al., 2008). Expression of reporter genes was affected by selected IF1 mutants in a TIR-dependent manner, underscoring the importance of IF1 in modulating the initiation efficiency (Surkov et al., 2010). The 30S IC with an optimal mRNA and correctly bound tRNA provides a structural landscape that is favorable for 50S subunit docking (Grigoriadou et al., 2007a; Milon et al., 2008; Simonetti et al., 2008; Julian et al., 2011) (high $\mathrm{k}_{4}$ value) while the presence of an unfavorable mRNA delays 70S IC formation, thereby decreasing the translation efficiency of that mRNA (Milon et al., 2008). Again, the conformation of the $30 \mathrm{~S}$ subunit is crucial, as mutations in the 30 S subunit that were isolated in IF1-dependent screens and do not involve intersubunit bridges affect the $50 \mathrm{~S}$ subunit association (Belotserkovsky et al., 2011). In addition, those $30 \mathrm{~S}$ complexes on which codon-anticodon interaction is not perfect may dissociate faster (high $\mathrm{k}_{-3}$ value). Thus, the selection of mRNA and tRNA is achieved at several consecutive kinetic partitioning checkpoints which favor the forward steps for good substrates and disfavor or delay the entry of poor substrates further into initiation.

The selection against non-initiator tRNA provides a particularly good example for the importance of kinetic partitioning in initiation. The rate of the $50 \mathrm{~S}$ subunit docking to the 30S IC is influenced by the nature of the tRNA: when the 30S IC is formed with Met-tRNA ${ }^{\text {fMet }}$ or PhetRNA $^{\text {Phe }}$, the rate of $50 \mathrm{~S}$ subunit joining is $60-400$ times lower than with the complex containing fMet-tRNA ${ }^{\mathrm{fMet}}$ (Antoun et al., 2006a). This remarkable difference is observed only in the presence of IF3, which appears to

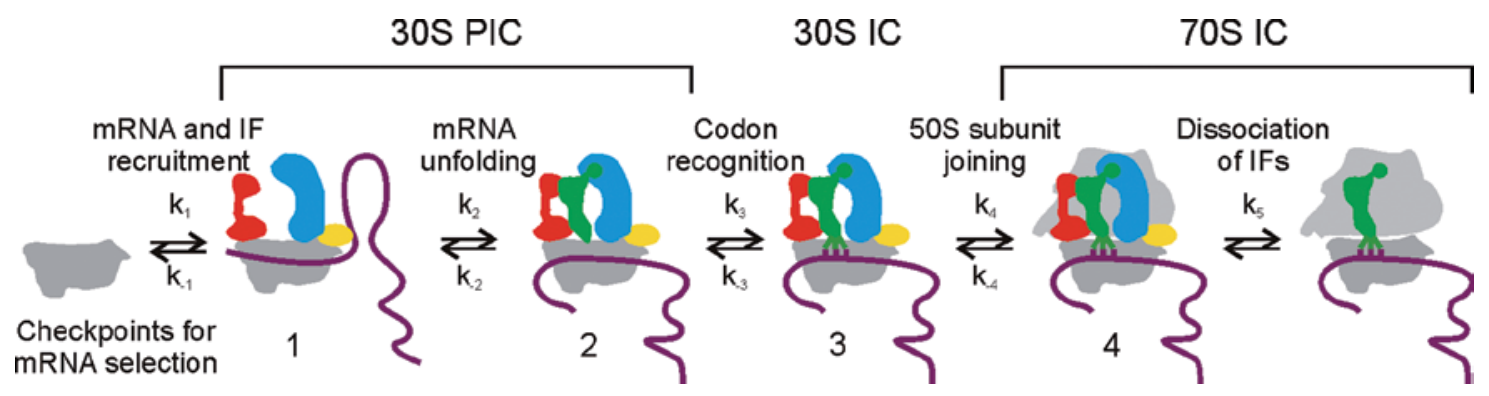

Figure 8. Kinetic partitioning mechanism of mRNA selection. Checkpoint 1, initial docking complex with mRNA bound to the platform of the 30S subunit (Marzi et al., 2007). Checkpoint 2, mature 30S PIC. The step indicated as mRNA unfolding may entail a number or further intermediates, e.g. the formation of a stable SD-aSD interaction, rearrangements of the 30S subunit, and possibly the initial start codon sampling. As this checkpoint, mostly the secondary structure of the TIR is monitored. Recruitment of fMet-tRNA ${ }^{\mathrm{fMet}}$ to $30 \mathrm{~S}$ PIC, which is not shown as a separate step, constitutes a control checkpoint for the selection of fMet-tRNA ${ }^{\mathrm{fMet}}$ against all other aminoacyl-tRNA due to the specific interactions with IF2. Checkpoint 3, 30S IC. Codon recognition is probably a composite step that triggers the stabilization of fMet-tRNA ${ }^{\mathrm{fMet}}$ and destabilization of IF3 binding and promotes further conformational changes in the 30S IC; checkpoint 3 selects against mismatches in the codon-anticodon complex. Checkpoint 4, early 70S IC. Here, the fine properties of the TIR are sensed (Milon et al., 2008). (See colour version of this figure online at www.informahealthcare.com/bmg) 
destabilize tRNA binding and prevent $50 \mathrm{~S}$ joining to a similar extent with any tRNA. However, the dissociation of fMet-tRNA ${ }^{\mathrm{fMet}}$ from the 30S IC remains significantly slower than the rate of $50 \mathrm{~S}$ subunit joining, such that the tRNA is retained and the 30S IC can rearrange to the 70S IC. In contrast, the dissociation of Met-tRNA ${ }^{\mathrm{fMet}}$ or PhetRNA $^{\text {Phe }}$ is much faster than 50S subunit docking; as a result, incorrect tRNAs are discarded before the 70S IC can form and enter translation. An analogous selection mechanism applies when fMet-tRNA ${ }^{\mathrm{fMet}}$ in the $30 \mathrm{~S}$ complex is bound to a near-cognate codon: the dissociation of the near-cognate 30S IC is faster, and the docking of the 50S subunit much slower, compared to the cognate complex (Milon et al., 2008). As in the selection of the TIR described above, conformational rearrangements operated by the codon-dependent affinity switch alter the structural landscape of the 30S IC which is sensed by the $50 \mathrm{~S}$ subunit, thereby affecting the rate of the transition to the 70S IC.

\section{Perspectives}

Our understanding of fundamental aspects of de novo translation initiation has been greatly enriched recently and the future challenge will be to study other types of initiation, including the initiation on non-SD-led mRNAs and leaderless mRNAs. It will be important to work with full-length natural mRNAs in order to understand the level of complexity that is brought about by mRNA folding and unfolding on the ribosome. The less characterized mechanisms of coupled transcription/translation initiation and re-initiation should be further studied using the full richness of modern in vitro techniques. The major challenge for structural studies is the structure and dynamics of the 30S PIC, which has not been solved so far. Finally, the most exciting goal will be to follow how the ribosome transfers the environmental signals into changes in the proteome by modulating the kinetic checkpoints of initiation. Due to the progress in genomics, proteomics, biophysical techniques and structural methods, these questions are now within reach.

\section{Acknowledgments}

We thank Wolfgang Wintermeyer for critical reading of the manuscript.

\section{Declaration of interest}

We acknowledge funding from the Max Planck Society and the Deutsche Forschungsgesellschaft.

\section{References}

Allen GS, Frank J. 2007. Structural insights on the translation initiation complex: ghosts of a universal initiation complex. Mol Microbiol 63:941-950.

Allen GS, Zavialov A, Gursky R, Ehrenberg M, Frank J. 2005. The cryo-EM structure of a translation initiation complex from Escherichia coli. Cell 121:703-712.
Allert M, Cox JC, Hellinga HW. 2010. Multifactorial determinants of protein expression in prokaryotic open reading frames. J Mol Biol 402:905-918.

Antoun A, Pavlov MY, Andersson K, Tenson T, Ehrenberg M. 2003. The roles of initiation factor 2 and guanosine triphosphate in initiation of protein synthesis. EMBO J 22:5593-5601.

Antoun A, Pavlov MY, Lovmar M, Ehrenberg M. 2006a. How initiation factors maximize the accuracy of tRNA selection in initiation of bacterial protein synthesis. Mol Cell 23:183-193.

Antoun A, Pavlov MY, Lovmar M, Ehrenberg M. 2006b. How initiation factors tune the rate of initiation of protein synthesis in bacteria. EMBO J 25:2539-2550.

Baudet M, Ortet P, Gaillard JC, Fernandez B, Guérin P, Enjalbal C, Subra G, de Groot A, Barakat M, Dedieu A, Armengaud J. 2010. Proteomics-based refinement of Deinococcus deserti genome annotation reveals an unwonted use of non-canonical translation initiation codons. Mol Cell Proteomics 9:415-426.

Belotserkovsky JM, Dabbs ER, Isaksson LA. 2011. Mutations in 16S rRNA that suppress cold-sensitive initiation factor 1 affect ribosomal subunit association. FEBS J 278:3508-3517.

Bernstein JA, Khodursky AB, Lin PH, Lin-Chao S, Cohen SN. 2002. Global analysis of mRNA decay and abundance in Escherichia coli at single-gene resolution using two-color fluorescent DNA microarrays. Proc Natl Acad Sci USA 99:9697-9702.

Binns N, Masters M. 2002. Expression of the Escherichia coli pcnB gene is translationally limited using an inefficient start codon: a second chromosomal example of translation initiated at AUU. Mol Microbiol 44:1287-1298.

Biou V, Shu F, Ramakrishnan V. 1995. X-ray crystallography shows that translational initiation factor IF3 consists of two compact $\alpha / \beta$ domains linked by an alpha-helix. EMBO J 14:4056-4064.

Boelens R, Gualerzi CO. 2002. Structure and function of bacterial initiation factors. Curr Protein Pept Sci 3:107-119.

Boni IV, Isaeva DM, Musychenko ML, Tzareva NV. 1991. Ribosomemessenger recognition: mRNA target sites for ribosomal protein S1. Nucleic Acids Res 19:155-162.

Calogero RA, Pon CL, Canonaco MA, Gualerzi CO. 1988. Selection of the mRNA translation initiation region by Escherichia coli ribosomes. Proc Natl Acad Sci USA 85:6427-6431.

Canonaco MA, Calogero RA, Gualerzi CO. 1986. Mechanism of translational initiation in prokaryotes. Evidence for a direct effect of IF2 on the activity of the $30 \mathrm{~S}$ ribosomal subunit. FEBS Lett 207:198-204.

Canonaco MA, Gualerzi CO, Pon CL. 1989. Alternative occupancy of a dual ribosomal binding site by mRNA affected by translation initiation factors. Eur J Biochem 182:501-506.

Carter AP, Clemons WM Jr, Brodersen DE, Morgan-Warren RJ, Hartsch T, Wimberly BT, Ramakrishnan V. 2001. Crystal structure of an initiation factor bound to the $30 \mathrm{~S}$ ribosomal subunit. Science 291:498-501.

Caserta E, Tomsic J, Spurio R, La Teana A, Pon CL, Gualerzi CO. 2006. Translation initiation factor IF2 interacts with the $30 \mathrm{~S}$ ribosomal subunit via two separate binding sites. J Mol Biol 362: 787-799.

Chang B, Halgamuge S, Tang SL. 2006. Analysis of SD sequences in completed microbial genomes: non-SD-led genes are as common as SD-led genes. Gene 373:90-99.

Dallas A, Noller HF. 2001. Interaction of translation initiation factor 3 with the 30S ribosomal subunit. Mol Cell 8:855-864.

de Smit MH, van Duin J. 1994. Translational initiation on structured messengers. Another role for the Shine-Dalgarno interaction. J Mol Biol 235:173-184.

Debey P, Hui Bon Hoa G, Douzou P, Godefroy-Colburn T, Graffe M, Grunberg-Manago M. 1975. Ribosomal subunit interaction as studied by light scattering. Evidence of different classes of ribosome preparations. Biochemistry 14:1553-1559.

Dreyfus M. 1988. What constitutes the signal for the initiation of protein synthesis on Escherichia coli mRNAs? J Mol Biol 204:79-94. 
Fabbretti A, Pon CL, Hennelly SP, Hill WE, Lodmell JS, Gualerzi CO. 2007. The real-time path of translation factor IF3 onto and off the ribosome. Mol Cell 25:285-296.

Garcia C, Fortier PL, Blanquet S, Lallemand JY, Dardel F. 1995. Solution structure of the ribosome-binding domain of $E$. coli translation initiation factor IF3. Homology with the U1A protein of the eukaryotic spliceosome. J Mol Biol 254:247-259.

Geissmann T, Marzi S, Romby P. 2009. The role of mRNA structure in translational control in bacteria. RNA Biol 6:153-160.

Gold L. 1988. Posttranscriptional regulatory mechanisms in Escherichia coli. Annu Rev Biochem 57:199-233.

Grigoriadou C, Marzi S, Kirillov S, Gualerzi CO, Cooperman BS. 2007a. A quantitative kinetic scheme for $70 \mathrm{~S}$ translation initiation complex formation. J Mol Biol 373:562-572.

Grigoriadou C, Marzi S, Pan D, Gualerzi CO, Cooperman BS. 2007b. The translational fidelity function of IF3 during transition from the $30 \mathrm{~S}$ initiation complex to the $70 \mathrm{~S}$ initiation complex. J Mol Biol 373:551-561.

Grill S, Gualerzi CO, Londei P, Bläsi U. 2000. Selective stimulation of translation of leaderless mRNA by initiation factor 2: evolutionary implications for translation. EMBO J 19:4101-4110.

Grill S, Moll I, Giuliodori AM, Gualerzi CO, Bläsi U. 2002. Temperaturedependent translation of leaderless and canonical mRNAs in Escherichia coli. FEMS Microbiol Lett 211:161-167.

Gualerzi C, Risuleo G, Pon CL. 1977. Initial rate kinetic analysis of the mechanism of initiation complex formation and the role of initiation factor IF-3. Biochemistry 16:1684-1689.

Gualerzi CO, Brandi L, Caserta E, Garofalo C, Lammi M, La Teana A, Petrelli D, Spurio R, Tomsic J, Pon CL. 2001. Initiation factors in the early events of mRNA translation in bacteria. Cold Spring Harb Symp Quant Biol 66:363-376.

Gualerzi CO, Pon CL. 1990. Initiation of mRNA translation in prokaryotes. Biochemistry 29:5881-5889.

Gualerzi CO, Wintermeyer W. 1986. Prokaryotic initiation factor 2 acts at the level of the $30 \mathrm{~S}$ ribosomal subunit. A fluorescence stoppedflow study. FEBS Lett 202:1-6.

Guenneugues M, Caserta E, Brandi L, Spurio R, Meunier S, Pon CL, Boelens R, Gualerzi CO. 2000. Mapping the fMet-tRNA(f)(Met) binding site of initiation factor IF2. EMBO J 19:5233-5240.

Hartz D, Binkley J, Hollingsworth T, Gold L. 1990. Domains of initiator tRNA and initiation codon crucial for initiator tRNA selection by Escherichia coli IF3. Genes Dev 4:1790-1800.

Hartz D, McPheeters DS, Gold L. 1989. Selection of the initiator tRNA by Escherichia coli initiation factors. Genes Dev 3:1899-1912.

Hauryliuk V, Mitkevich VA, Draycheva A, Tankov S, Shyp V, Ermakov A, Kulikova AA, Makarov AA, Ehrenberg M. 2009. Thermodynamics of GTP and GDP binding to bacterial initiation factor 2 suggests two types of structural transitions. J Mol Biol 394:621-626.

Hennelly SP, Antoun A, Ehrenberg M, Gualerzi CO, Knight W, Lodmell JS, Hill WE. 2005. A time-resolved investigation of ribosomal subunit association. J Mol Biol 346:1243-1258.

Huang C, Mandava CS, Sanyal S. 2010. The ribosomal stalk plays a key role in IF2-mediated association of the ribosomal subunits. J Mol Biol 399:145-153.

Hui A, de Boer HA. 1987. Specialized ribosome system: preferential translation of a single mRNA species by a subpopulation of mutated ribosomes in Escherichia coli. Proc Natl Acad Sci USA 84:4762-4766.

Jacob WF, Santer M, Dahlberg AE. 1987. A single base change in the Shine-Dalgarno region of 16S rRNA of Escherichia coli affects translation of many proteins. Proc Natl Acad Sci USA 84:4757-4761.

Jacques N, Dreyfus M. 1990. Translation initiation in Escherichia coli: old and new questions. Mol Microbiol 4:1063-1067.

Jenner L, Romby P, Rees B, Schulze-Briese C, Springer M, Ehresmann C, Ehresmann B, Moras D, Yusupova G, Yusupov M. 2005. Translational operator of mRNA on the ribosome: how repressor proteins exclude ribosome binding. Science 308:120-123.
Jin H, Zhao Q, Gonzalez de Valdivia EI, Ardell DH, Stenström M, Isaksson LA. 2006. Influences on gene expression in vivo by a Shine-Dalgarno sequence. Mol Microbiol 60:480-492.

Julián P, Milon P, Agirrezabala X, Lasso G, Gil D, Rodnina MV, Valle M. 2011. The Cryo-EM structure of a complete $30 \mathrm{~S}$ translation initiation complex from Escherichia coli. PLoS Biol 9:e1001095.

Kaberdina AC, Szaflarski W, Nierhaus KH, Moll I. 2009. An unexpected type of ribosomes induced by kasugamycin: a look into ancestral times of protein synthesis? Mol Cell 33:227-236.

Karimi R, Pavlov MY, Buckingham RH, Ehrenberg M. 1999. Novel roles for classical factors at the interface between translation termination and initiation. Mol Cell 3:601-609.

Katz L, Burge CB. 2003. Widespread selection for local RNA secondary structure in coding regions of bacterial genes. Genome Res 13:2042-2051.

Kitakawa M, Isono K. 1982. An amber mutation in the gene rpsA for ribosomal protein S1 in Escherichia coli. Mol Gen Genet 185:445-447.

Komarova AV, Tchufistova LS, Supina EV, Boni IV. 2002. Protein S1 counteracts the inhibitory effect of the extended Shine-Dalgarno sequence on translation. RNA 8:1137-1147.

Krishnan KM, Van Etten WJ 3rd, Janssen GR. 2010. Proximity of the start codon to a leaderless mRNA's 5' terminus is a strong positive determinant of ribosome binding and expression in Escherichia coli. J Bacteriol 192:6482-6485.

Kudla G, Murray AW, Tollervey D, Plotkin JB. 2009. Coding-sequence determinants of gene expression in Escherichia coli. Science 324:255-258.

La Teana A, Gualerzi CO, Brimacombe R. 1995. From stand-by to decoding site. Adjustment of the mRNA on the 30S ribosomal subunit under the influence of the initiation factors. RNA 1:772-782.

La Teana A, Pon CL, Gualerzi CO. 1993. Translation of mRNAs with degenerate initiation triplet AUU displays high initiation factor 2 dependence and is subject to initiation factor 3 repression. Proc Natl Acad Sci USA 90:4161-4165.

Lancaster L, Noller HF. 2005. Involvement of 16S rRNA nucleotides G1338 and A1339 in discrimination of initiator tRNA. Mol Cell 20:623-632.

Laursen BS, Mortensen KK, Sperling-Petersen HU, Hoffman DW. 2003. A conserved structural motif at the $\mathrm{N}$ terminus of bacterial translation initiation factor IF2. J Biol Chem 278:16320-16328.

Laursen BS, Sørensen HP, Mortensen KK, Sperling-Petersen HU. 2005. Initiation of protein synthesis in bacteria. Microbiol Mol Biol Rev 69:101-123.

Lee K, Holland-Staley CA, Cunningham PR. 1996. Genetic analysis of the Shine-Dalgarno interaction: selection of alternative functional mRNA-rRNA combinations. RNA 2:1270-1285.

Lomakin IB, Shirokikh NE, Yusupov MM, Hellen CU, Pestova TV. 2006. The fidelity of translation initiation: reciprocal activities of eIF1, IF3 and YciH. EMBO J 25:196-210.

Ma J, Campbell A, Karlin S. 2002. Correlations between ShineDalgarno sequences and gene features such as predicted expression levels and operon structures. J Bacteriol 184:5733-5745.

Maar D, Liveris D, Sussman JK, Ringquist S, Moll I, Heredia N, Kil A, Bläsi U, Schwartz I, Simons RW. 2008. A single mutation in the IF3 $\mathrm{N}$-terminal domain perturbs the fidelity of translation initiation at three levels. J Mol Biol 383:937-944.

Mandal N, Mangroo D, Dalluge JJ, McCloskey JA, Rajbhandary UL. 1996. Role of the three consecutive G:C base pairs conserved in the anticodon stem of initiator tRNAs in initiation of protein synthesis in Escherichia coli. RNA 2:473-482.

Mandava CS, Peisker K, Ederth J, Kumar R, Ge X, Szaflarski W, Sanyal S. 2012. Bacterial ribosome requires multiple L12 dimers for efficient initiation and elongation of protein synthesis involving IF2 and EF-G. Nucleic Acids Res 40:2054-2064.

Marshall RA, Aitken CE, Puglisi JD. 2009. GTP hydrolysis by IF2 guides progression of the ribosome into elongation. Mol Cell 35:37-47. 
Marzi S, Myasnikov AG, Serganov A, Ehresmann C, Romby P, Yusupov M, Klaholz BP. 2007. Structured mRNAs regulate translation initiation by binding to the platform of the ribosome. Cell 130:1019-1031.

McCutcheon JP, Agrawal RK, Philips SM, Grassucci RA, Gerchman SE, Clemons WM Jr, Ramakrishnan V, Frank J. 1999. Location of translational initiation factor IF3 on the small ribosomal subunit. Proc Natl Acad Sci USA 96:4301-4306.

Melançon P, Leclerc D, Destroismaisons N, Brakier-Gingras L. 1990. The anti-Shine-Dalgarno region in Escherichia coli $16 \mathrm{~S}$ ribosomal RNA is not essential for the correct selection of translational starts. Biochemistry 29:3402-3407.

Meunier S, Spurio R, Czisch M, Wechselberger R, Guenneugues M, Gualerzi CO, Boelens R. 2000. Structure of the fMet-tRNA(fMet)binding domain of $B$. stearothermophilus initiation factor IF2. EMBO J 19:1918-1926.

Milon P, Carotti M, Konevega AL, Wintermeyer W, Rodnina MV, Gualerzi CO. 2010. The ribosome-bound initiation factor 2 recruits initiator tRNA to the 30S initiation complex. EMBO Rep 11:312-316.

Milon P, Konevega AL, Gualerzi CO, Rodnina MV. 2008. Kinetic checkpoint at a late step in translation initiation. Mol Cell 30:712-720.

Milon P, Maracci C, Filonava L, Gualerzi CO, Rodnina MV. 2012. Realtime assembly landscape of bacterial 30S translation initiation complex. Nat Struct Mol Biol (In Press).

Milon P, Tischenko E, Tomsic J, Caserta E, Folkers G, La Teana A, Rodnina MV, Pon CL, Boelens R, Gualerzi CO. 2006. The nucleotide-binding site of bacterial translation initiation factor 2 (IF2) as a metabolic sensor. Proc Natl Acad Sci USA 103:13962-13967.

Mitarai N, Sneppen K, Pedersen S. 2008. Ribosome collisions and translation efficiency: optimization by codon usage and mRNA destabilization. J Mol Biol 382:236-245.

Mitkevich VA, Ermakov A, Kulikova AA, Tankov S, Shyp V, Soosaar A, Tenson T, Makarov AA, Ehrenberg M, Hauryliuk V. 2010. Thermodynamic characterization of ppGpp binding to EF-G or IF2 and of initiator tRNA binding to free IF2 in the presence of GDP, GTP, or ppGpp. J Mol Biol 402:838-846.

Moll I, Grill S, Gründling A, Bläsi U. 2002. Effects of ribosomal proteins S1, S2 and the DeaD/CsdA DEAD-box helicase on translation of leaderless and canonical mRNAs in Escherichia coli. Mol Microbiol 44:1387-1396.

Moreno JM, Drskjøtersen L, Kristensen JE, Mortensen KK, SperlingPetersen HU. 1999. Characterization of the domains of E. coli initiation factor IF2 responsible for recognition of the ribosome. FEBS Lett 455:130-134.

Mortensen KK, Kildsgaard J, Moreno JM, Steffensen SA, Egebjerg J, Sperling-Petersen HU. 1998. A six-domain structural model for Escherichia coli translation initiation factor IF2. Characterisation of twelve surface epitopes. Biochem Mol Biol Int 46:1027-1041.

Myasnikov AG, Marzi S, Simonetti A, Giuliodori AM, Gualerzi CO, Yusupova G, Yusupov M, Klaholz BP. 2005. Conformational transition of initiation factor 2 from the GTP- to GDP-bound state visualized on the ribosome. Nat Struct Mol Biol 12:1145-1149.

Myasnikov AG, Simonetti A, Marzi S, Klaholz BP. 2009. Structurefunction insights into prokaryotic and eukaryotic translation initiation. Curr Opin Struct Biol 19:300-309.

Nakamoto T. 2006. A unified view of the initiation of protein synthesis. Biochem Biophys Res Commun 341:675-678.

O'Connor M, Gregory ST, Rajbhandary UL, Dahlberg AE. 2001. Altered discrimination of start codons and initiator tRNAs by mutant initiation factor 3. RNA 7:969-978.

O'Connor M, Thomas CL, Zimmermann RA, Dahlberg AE. 1997. Decoding fidelity at the ribosomal A and P sites: influence of mutations in three different regions of the decoding domain in $16 \mathrm{~S}$ rRNA. Nucleic Acids Res 25:1185-1193.

Passalacqua KD, Varadarajan A, Ondov BD, Okou DT, Zwick ME, Bergman NH. 2009. Structure and complexity of a bacterial transcriptome. J Bacteriol 191:3203-3211.
Pavlov MY, Zorzet A, Andersson DI, Ehrenberg M. 2011. Activation of initiation factor 2 by ligands and mutations for rapid docking of ribosomal subunits. EMBO J 30:289-301.

Peske F, Rodnina MV, Wintermeyer W. 2005. Sequence of steps in ribosome recycling as defined by kinetic analysis. Mol Cell 18:403-412.

Petrelli D, LaTeana A, Garofalo C, Spurio R, Pon CL, Gualerzi CO. 2001. Translation initiation factor IF3: two domains, five functions, one mechanism? EMBO J 20:4560-4569.

Polard P, Prère MF, Chandler M, Fayet O. 1991. Programmed translational frameshifting and initiation at an AUU codon in gene expression of bacterial insertion sequence IS911. J Mol Biol 222:465-477.

Pon CL, Paci M, Pawlik RT, Gualerzi CO. 1985. Structure-function relationship in Escherichia coli initiation factors. Biochemical and biophysical characterization of the interaction between IF-2 and guanosine nucleotides. J Biol Chem 260:8918-8924.

Proshkin S, Rahmouni AR, Mironov A, Nudler E. 2010. Cooperation between translating ribosomes and RNA polymerase in transcription elongation. Science 328:504-508.

Qin D, Abdi NM, Fredrick K. 2007. Characterization of 16S rRNA mutations that decrease the fidelity of translation initiation. RNA 13:2348-2355.

Qin D, Fredrick K. 2009. Control of translation initiation involves a factor-induced rearrangement of helix 44 of $16 \mathrm{~S}$ ribosomal RNA. Mol Microbiol 71:1239-1249.

Qin D, Liu Q, Devaraj A, Fredrick K. 2012. Role of helix 44 of 16S rRNA in the fidelity of translation initiation. RNA 18:485-495.

Ringquist S, Jones T, Snyder EE, Gibson T, Boni I, Gold L. 1995. Highaffinity RNA ligands to Escherichia coli ribosomes and ribosomal protein S1: comparison of natural and unnatural binding sites. Biochemistry 34:3640-3648.

Roll-Mecak A, Cao C, Dever TE, Burley SK. 2000. X-Ray structures of the universal translation initiation factor IF2/eIF5B: conformational changes on GDP and GTP binding. Cell 103:781-792.

Scharff LB, Childs L, Walther D, Bock R. 2011. Local absence of secondary structure permits translation of mRNAs that lack ribosome-binding sites. PLoS Genet 7:e1002155.

Schuwirth BS, Borovinskaya MA, Hau CW, Zhang W, Vila-Sanjurjo A, Holton JM, Cate JH. 2005. Structures of the bacterial ribosome at 3.5 A resolution. Science 310:827-834.

Sengupta J, Agrawal RK, Frank J. 2001. Visualization of protein S1 within the $30 \mathrm{~S}$ ribosomal subunit and its interaction with messenger RNA. Proc Natl Acad Sci USA 98:11991-11996.

Seong BL, RajBhandary UL. 1987. Escherichia coli formylmethionine tRNA: mutations in GGGCCC sequence conserved in anticodon stem of initiator tRNAs affect initiation of protein synthesis and conformation of anticodon loop. Proc Natl Acad Sci USA 84:334-338.

Sette M, Spurio R, van Tilborg P, Gualerzi CO, Boelens R. 1999. Identification of the ribosome binding sites of translation initiation factor IF3 by multidimensional heteronuclear NMR spectroscopy. RNA 5:82-92.

Sette M, van Tilborg P, Spurio R, Kaptein R, Paci M, Gualerzi CO, Boelens R. 1997. The structure of the translational initiation factor IF1 from E. coli contains an oligomer-binding motif. EMBO J 16:1436-1443.

Simonetti A, Marzi S, Jenner L, Myasnikov A, Romby P, Yusupova G, Klaholz BP, Yusupov M. 2009. A structural view of translation initiation in bacteria. Cell Mol Life Sci 66:423-436.

Simonetti A, Marzi S, Myasnikov A, Menetret J-P, Klaholz BP. 2011. Insights into translation initiation and termination complexes and into the polysome architecture. In: Rodnina MV, Wintermeyer W, Green R, editors. Ribosomes Structure, Function, and Dynamics. Wien, New York: Springer, 113-128

Simonetti A, Marzi S, Myasnikov AG, Fabbretti A, Yusupov M, Gualerzi CO, Klaholz BP. 2008. Structure of the 30S translation initiation complex. Nature 455:416-420. 
Skorski P, Leroy P, Fayet O, Dreyfus M, Hermann-Le Denmat S. 2006. The highly efficient translation initiation region from the Escherichia coli rpsA gene lacks a Shine-Dalgarno element. J Bacteriol 188:6277-6285.

Sørensen MA, Fricke J, Pedersen S. 1998. Ribosomal protein S1 is required for translation of most, if not all, natural mRNAs in Escherichia coli in vivo. J Mol Biol 280:561-569.

Studer SM, Joseph S. 2006. Unfolding of mRNA secondary structure by the bacterial translation initiation complex. Mol Cell 22:105-115.

Surkov S, Nilsson H, Rasmussen LC, Sperling-Petersen HU, Isaksson LA. 2010. Translation initiation region dependency of translation initiation in Escherichia coli by IF1 and kasugamycin. FEBS J 277:2428-2439.

Sussman JK, Simons EL, Simons RW. 1996. Escherichia coli translation initiation factor 3 discriminates the initiation codon in vivo. Mol Microbiol 21:347-360.

Tapprich WE, Goss DJ, Dahlberg AE. 1989. Mutation at position 791 in Escherichia coli $16 \mathrm{~S}$ ribosomal RNA affects processes involved in the initiation of protein synthesis. Proc Natl Acad Sci USA 86:4927-4931.

Tolstrup N, Sensen CW, Garrett RA, Clausen IG. 2000. Two different and highly organized mechanisms of translation initiation in the archaeon Sulfolobus solfataricus. Extremophiles 4:175-179.

Tomsic J, Vitali LA, Daviter T, Savelsbergh A, Spurio R, Striebeck P, Wintermeyer W, Rodnina MV, Gualerzi CO. 2000. Late events of translation initiation in bacteria: a kinetic analysis. EMBO J 19:2127-2136.

Tuller T, Waldman YY, Kupiec M, Ruppin E. 2010. Translation efficiency is determined by both codon bias and folding energy. Proc Natl Acad Sci USA 107:3645-3650.

Van Etten WJ, Janssen GR. 1998. An AUG initiation codon, not codonanticodon complementarity, is required for the translation of unleadered mRNA in Escherichia coli. Mol Microbiol 27:987-1001.

Vesper O, Amitai S, Belitsky M, Byrgazov K, Kaberdina AC, EngelbergKulka H, Moll I. 2011. Selective translation of leaderless mRNAs by specialized ribosomes generated by MazF in Escherichia coli. Cell 147:147-157.
Vimberg V, Tats A, Remm M, Tenson T. 2007. Translation initiation region sequence preferences in Escherichia coli. BMC Mol Biol 8:100.

Voges D, Watzele M, Nemetz C, Wizemann S, Buchberger B. 2004. Analyzing and enhancing mRNA translational efficiency in an Escherichia coli in vitro expression system. Biochem Biophys Res Commun 318:601-614.

Vohlander Rasmussen LC, Oliveira CL, Pedersen JS, Sperling-Petersen HU, Mortensen KK. 2011. Structural transitions of translation initiation factor IF2 upon GDPNP and GDP binding in solution. Biochemistry 50:9779-9787.

Weiner J 3rd, Herrmann R, Browning GF. 2000. Transcription in Mycoplasma pneumoniae. Nucleic Acids Res 28:4488-4496.

Wienk H, Tishchenko E, Belardinelli R, Tomaselli S, Dongre R, Spurio R, Folkers GE, Gualerzi CO, Boelens R. 2012. Structural dynamics of bacterial translation initiation factor IF2. J Biol Chem 287:10922-10932.

Wienk H, Tomaselli S, Bernard C, Spurio R, Picone D, Gualerzi CO, Boelens R. 2005. Solution structure of the C1-subdomain of Bacillus stearothermophilus translation initiation factor IF2. Protein Sci 14:2461-2468.

Wintermeyer W, Gualerzi C. 1983. Effect of Escherichia coli initiation factors on the kinetics of N-Acphe-tRNAPhe binding to $30 \mathrm{~S}$ ribosomal subunits. A fluorescence stopped-flow study. Biochemistry 22:690-694.

Yoo JH, RajBhandary UL. 2008. Requirements for translation re-initiation in Escherichia coli: roles of initiator tRNA and initiation factors IF2 and IF3. Mol Microbiol 67: 1012-1026.

Yusupova G, Jenner L, Rees B, Moras D, Yusupov M. 2006. Structural basis for messenger RNA movement on the ribosome. Nature 444:391-394.

Zheng X, Hu GQ, She ZS, Zhu H. 2011. Leaderless genes in bacteria: clue to the evolution of translation initiation mechanisms in prokaryotes. BMC Genomics 12:361.

Zorzet A, Pavlov MY, Nilsson AI, Ehrenberg M, Andersson DI. 2010. Error-prone initiation factor 2 mutations reduce the fitness cost of antibiotic resistance. Mol Microbiol 75:1299-1313. 